\title{
CHILD-CENTERED GROUP PLAY THERAPY WITH CHILDREN WITH SPEECH DIFFICULTIES
}

Suzan E. Danger, BS, MS

Dissertation Prepared for the Degree of DOCTOR OF PHILOSOPHY

\section{UNIVERSITY OF NORTH TEXAS}

August 2003

\section{APPROVED:}

Garry Landreth, Major Professor

Sue Bratton, Committee Member

Janice Holden, Committee Member and Program Coordinator

Michael Altekruse, Chair of the Department of Counseling, Development, and Higher Education

M. Jean Keller, Dean of the College of Education C. Neal Tate, Dean of the Robert B. Toulouse School of Graduate Studies 


\section{Danger, Suzan. Child-Centered Group Play Therapy with Children with Speech}

Difficulties. Doctor of Philosophy (Counseling), August 2003, 97 pages, 26 tables, references, 63 titles.

The problem with which this investigation was concerned was that of determining the efficacy of child-centered group play therapy with pre-kindergarten and kindergarten children with speech difficulties as an intervention strategy for improving specific speech problems in the areas of articulation, receptive language, and expressive language. A second purpose was that of determining the efficacy of child-centered group play therapy in improving self-esteem, positive social interaction, and in decreasing anxiety and withdrawal behaviors among pre-kindergarten and kindergarten children with speech difficulties.

The experimental group consisted of 11 children who received 25 group play therapy sessions one time a week in addition to their directive speech therapy sessions. The comparison group consisted of 10 children who received only their directive speech therapy sessions. The Goldman Fristoe Test of Articulation, the Peabody Picture Vocabulary Test - Revised, and the Clinical Evaluation of Language Fundamentals - 3 were used to measure receptive and expressive language skills. The Burks' Behavior Rating Scale was used to measure symptoms of anxiety, withdrawal, poor self-esteem, and poor social skills as observed by parents and teachers.

Twelve hypotheses were tested using ANCOVA and Eta Squared. Child-centered group play therapy was shown to have a large practical significance in helping children improve their expressive language skills. Child-centered group play therapy was shown to have a medium practical significance in increasing children's receptive language skills. Small sample size may have contributed to the lack of statistical significance as calculated by the analysis of covariance. Child-centered group play therapy was shown to have a small yet positive impact upon 
children's articulation skills and anxiety. Although not significant at the .05 level, these results indicate a slightly larger increase in articulation skills and a slightly larger decrease in symptoms of anxiety among those children who received group play therapy as compared to those who did not. Child-centered group play therapy was shown to have a mixed effect upon children's selfesteem, withdrawal behaviors, and positive social interactions.

This study supports the use of child-centered group play therapy as an effective intervention strategy for children with speech difficulties to improve expressive and receptive language skill development. 
Copyright 2003

by

Suzan Danger 


\section{Acknowledgements}

I would like to thank Dr. Garry Landreth for his knowledge and encouragement, Dr. Sue Bratton for her creativity, and Dr. Janice Holden for her writing expertise. Special thanks go to Kimberly Joiner, Yumi Ogawa, Jenny Findling, and Brandy Schumann for their support. I would also like to thank Brad Jeffries, speech pathologist and my research assistant, Sandra Hensley, school principal, and the Texas Association for Play Therapy for their generous research grant. Lastly, I would like to thank my family for their love and understanding. 


\section{TABLE OF CONTENTS}

LIST OF TABLES. V

\section{Chapter}

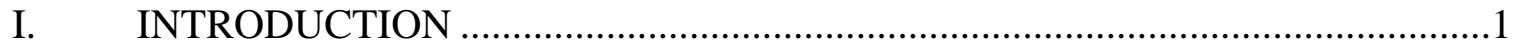

Statement of the Problem ...............................................................................

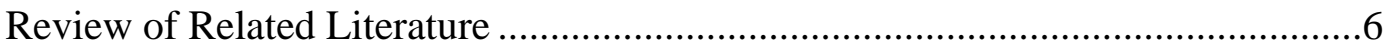

The Connection between Play and Language ...........................................6

Optimal Environmental Conditions for Language Learning ....................11

Current Trends and Outcomes in Speech Therapy Interventions ..............15

Specific Outcomes of Play Therapy Interventions ................................18

A Rationale for Group Play Therapy ...................................................21

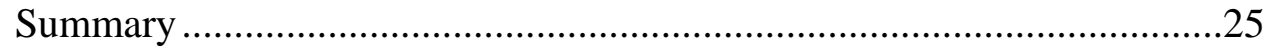

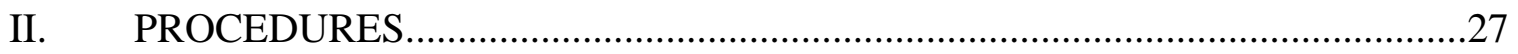

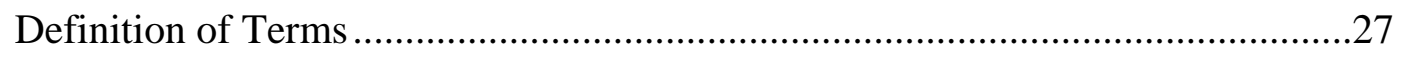

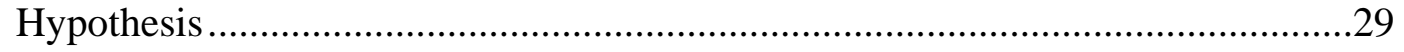

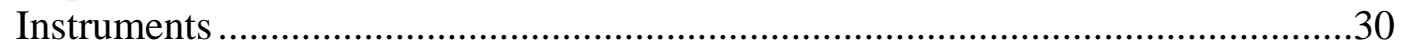

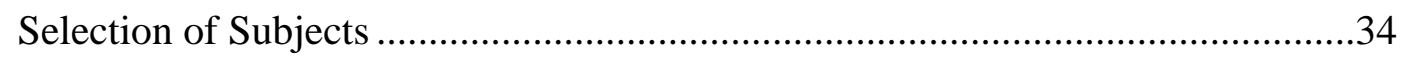

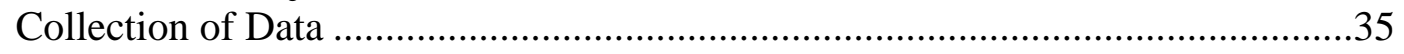

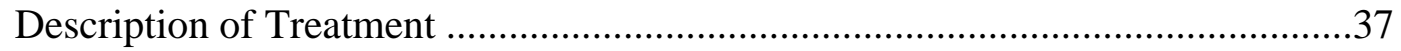

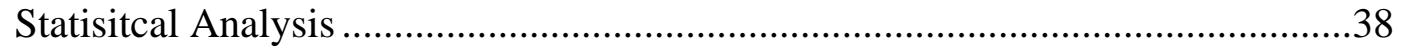

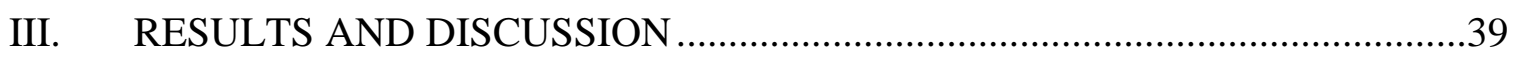

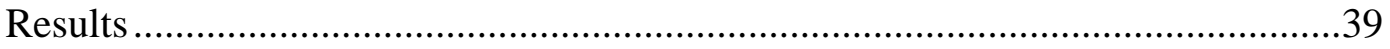

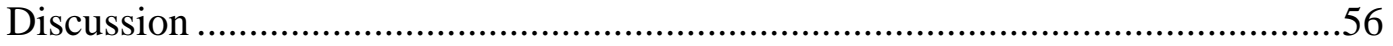

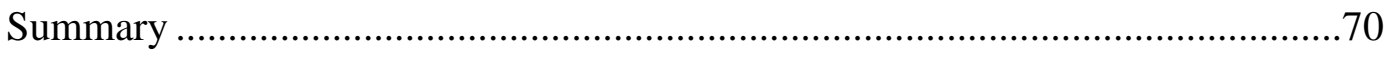

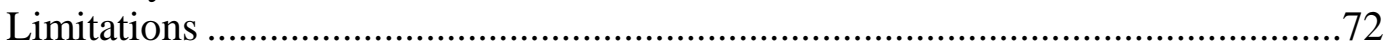

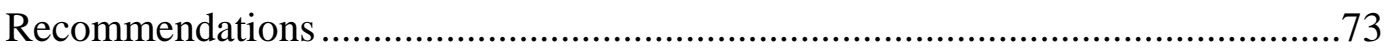

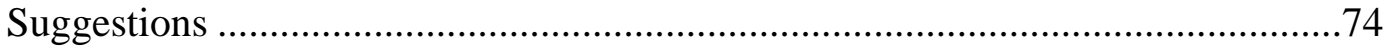

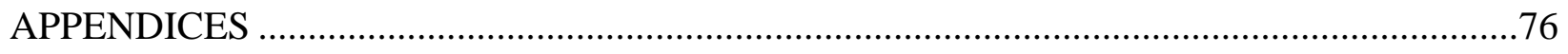

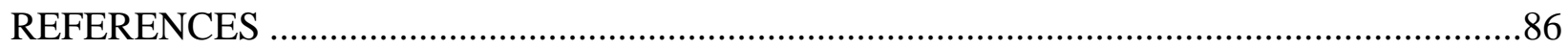




\section{LIST OF TABLES}

Table

1. Mean total scores on the Goldman Fristoe Test of Articulation (GFTA)

2. Analysis of covariance data for the Goldman Fristoe Test of Articulation (GFTA)

3. Mean total scores on the Peabody Picture Vocabulary

Test-Revised (PPVT-R)

4. Analysis of covariance data for the Peabody Picture Vocabulary

Test-Revised (PPVT-R)

5. Mean total scores on the Receptive Language sub-test of the

Clinical Evaluation of Language Fundamentals (CELF-3)

6. Analysis of covariance data for the Receptive Language sub-test of the Clinical Evaluation of Language Fundamentals Third Edition (CELF-3)

7. Mean total scores on the Expressive Language sub-test of the Clinical Evaluation of Language Fundamentals Third Edition (CELF-3) .43

8. Analysis of covariance data for the Expressive Language sub-test of the Clinical Evaluation of Language Fundamentals Third Edition (CELF-3)

9. Mean total scores on the Anxiety sub-test of the Burks' Behavior

Rating Scale as completed by participants' teachers

10. Analysis of covariance data for the Anxiety sub-test of the Burks'

Behavior Rating Scale as completed by participant's teachers

11. Mean total scores on the Anxiety sub-test of the Burks' Behavior

Rating Scale as completed by participants' parents

12. Analysis of covariance data for the Anxiety sub-test of the Burks'

Behavior Rating Scale as completed by participant's parents

13. Mean total scores on the Sense of Identity sub-test of the Burks'

Behavior Rating Scale as completed by participants' teachers 
14. Analysis of covariance data for the Sense of Identity sub-test of the Burks' Behavior Rating Scale as completed by participant's teachers

15. Mean total scores on the Sense of Identity sub-test of the Burks' Behavior Rating Scale as completed by participants' parents

16. Analysis of covariance data for the Sense of Identity sub-test of the Burks' Behavior Rating Scale as completed by participant's parents

17. Mean total scores on the Withdrawal sub-test of the Burks' Behavior Rating Scale as completed by participants' teachers

18. Analysis of covariance data for the Withdrawal sub-test of the Burks' Behavior Rating Scale as completed by participant's teachers

19. Mean total scores on the Withdrawal sub-test of the Burks' Behavior Rating Scale as completed by participants' parents

20. Analysis of covariance data for the Withdrawal sub-test of the Burks' Behavior Rating Scale as completed by participant's parents

21. Mean total scores on the Social Conformity sub-test of the Burks' Behavior Rating Scale as completed by participants' teachers

22. Analysis of covariance data for the Social Conformity sub-test of the Burks' Behavior Rating Scale as completed by participant's teachers

23. Mean total scores on the Social Conformity sub-test of the Burks' Behavior Rating Scale as completed by participants' parents

24. Analysis of covariance data for the Social Conformity sub-test of the Burks' Behavior Rating Scale as completed by participant's parents

25. Mean rating for amount of verbal expression during group play therapy sessions

26. Mean rating for amount of social interaction during group play therapy sessions 


\section{CHAPTER I}

\section{INTRODUCTION}

According to America's Children, a report published by the National Center of Health Statistics, $5.5 \%$ of America's children are limited in their ability to communicate: $7.2 \%$ of males and $3.8 \%$ of females. These limitations are defined as difficulties "for 12 months or more communicating with persons, family or non-family, difficulty understanding others, or a delay in speech development" (National Center for Health Statistics, p. 1). Indeed, children with speech difficulties represent the second largest group of children receiving specialized services in U.S. schools (Office of Educational Research and Improvement, 1990).

Of the 5.4 million children who qualify for services under the Elementary and Secondary Education Act (ESEA), 21.1\% of these children have speech or language impairments. This number is even greater for children in the specific age range of 6-11, representing a full $36.3 \%$ of all children receiving services under ESEA. Compared to those children who are mentally retarded $(11.6 \%)$, or emotionally disturbed (8.7\%), children with speech difficulties, as a group, are second in number only to children with cognitively based learning disabilities (Office of Educational Research and Improvement, 1990). Clearly, a large need exists for specialized interventions that effectively assist these language-impaired children.

Federal statistics show that $82 \%$ of speech impaired children who qualify for ESEA services are served in their regular classrooms, either through a modification of the regular curriculum by classroom teachers or through assisted language support by speech therapists in the classroom (Chartbook on Disabilities in the United States, 1996). The trend is to keep these children in the mainstream and to blend speech improvement and correction into the regular classroom curriculum. The literature in the field of speech therapy shows that traditionally, such speech interventions have taken the form of problem-targeted, therapist-directed, behavioral approaches designed to improve speech difficulties by focusing on specific, isolated speech 
deficits (Holm \& Dodd, 1999; Hubbell, 1981; Wade \& Haynes, 1986). However, as Landreth, Jacquot, and Allen (1969) stated, "just as ripples travel the entirety of the pond, disturbances reverberate throughout all the child's organism" (p. 25).

Literature in the field of language development suggests that children's emotional and social growth is negatively affected by disturbances in the acquisition of language. Cantwell and Baker (1980, as cited in Audet, Burke, Hummel, Maher, \& Theadore, 1990, p. 183) concluded, "it is a likely hypothesis that a handicap in the development of speech and language could predispose children to the development of psychiatric problems, since language is considered to be one of the main features that makes us human.” Research appears to bear this hypothesis out. Wakaba (1983), who studied Japanese children who stutter, concluded that a child's inability to communicate inhibits the opportunity to resolve inner conflicts, and the child eventually will be unable to recognize or express feelings when they occur. Audet et al. (1990) added that children with expressive language disorders find it "difficult to fully express their ideas, feelings, fears, and needs... and may misinterpret messages and are unable to request further information or clarification, resulting in confusion and frustration" (p.183). Axline (1947, p. 58) noted, "many times, the handicap is a frustrating and blocking experience that generates almost intolerable tensions within the child." Andronico and Blake's (1971) research with stuttering children yielded the conclusion that unsuccessful communication resulted in high anxiety which, in turn, solidified stuttering problems.

Audet et al. (1990) found that anxiety levels in children with speech difficulties were significantly correlated with the levels of their speech disorder. In a study by Baker and Cantwell (1992, as cited in Audet et al., 1990), 44\% of speech-impaired children were found to have some psychiatric illness diagnosed in accordance with the Diagnostic and Statistical Manual of Mental Disorders (American Psychological Association, 1994). Their follow-up study found that this number had increased to $60 \%$ after five years. Similar studies conducted in Canada by Beitman, Nair, Clegg, and Patel (1986, as cited in Audet et al., 1990, p. 181) indicated that of 182 speech- 
impaired children, $48.7 \%$ had psychiatric problems in addition to their communication problems. Stevenson and Richman (1976, as cited in Audet et al., 1990, p. 181) found that 59\% of 3 year old expressive language delayed children in England also had disturbances in behavior.

“...Disconnected from their genuine self...” (McGregor, 1993, p. 2), “...unable to separate appropriately...” (Bitler, 1993, p. 74), “...general affect is somber...” ( p. 75), “...engage in limited activities..." (p. 74) -- all of these phrases have been used to describe the speech impaired child. Research clearly acknowledges that emotional problems may be precipitated and perpetuated by difficulties in communication. One can logically speculate, as did Smathers and Tirnauer (1959), that working through emotional problems will theoretically "reverberate throughout the child's organism" (Landreth et al., 1969, p. 25) and positively impact speech development. Dupont, Landsman, and Valentine (1953) suggested that correction of emotional difficulties is the first step in any speech therapy intervention.

In addition to emotional influences, "an impairment in the use of language influences the way one functions in human relationships" (Hubbell, 1981, p. 123). Children who have language development disorders find it difficult to interact socially with people in their environment. Two studies cited by McAndrew (1999) seem to confirm this idea: Bishop (1994) determined that communication difficulties in children led to social rejection, and Adams (1995) found that peer interactions with language-impaired children were mostly negative.

Donahue and Hartas (1999) found that verbally withdrawn children had fewer action requests directed to their play partners. In addition, Audet et al. (1990) noted that children with speech difficulties, as a result of their frustration and anxiety, exhibit either externalizing behaviors, which include confrontations with peers or parents, or internalizing behaviors, which include withdrawing from peers or parents. McGregor (1993) wrote that such children "feel unable to impact positively on their environments and they have difficulty forming satisfying interpersonal relationships" (p. 2). Bitler (1976) observed immature interpersonal relationships 
and difficulties in engaging in age-appropriate play with peers among "communication handicapped" children (p. 74).

Play is an important dimension in the social interaction of children with speech difficulties. Hart (1976) noted that the play behaviors of speech delayed children are limited and disorganized, that they reflect themes of separation, and that children with language difficulties are limited in their ability to use play to re-create life experiences. Mogford-Bevan (1994) added to these findings with her conclusions that interactive play is difficult for speech-delayed children and that solitary play is usually predominant. In addition, she noted that such children "tend to have a more restricted range of play experiences by virtue of their disability" (p. 160). These conclusions support the contention that children with speech difficulties tend to be socially isolated in their play behaviors.

Noting that Wakaba (1983) determined that Japanese children with stuttering problems possessed delayed interpersonal relations and O'Connor (1991) wrote that children with speech difficulties tend to be targets of scapegoating by their peers, one can speculate that children with speech difficulties may experience negative social interactions. Because communication and interaction with others is the "central and most important motivational aspect of the speech learning process" (Formaad, 1974, p. 23), working to improve interpersonal relations seems to be another potentially successful means of impacting speech development.

In conclusion, a high rate of co-occurrence of speech disorders and emotional/social disorders in children has been documented in numerous studies in at least four countries. Therefore, a need exists for intervention strategies that address these social and emotional elements. Improvements in one area could, in theory, "ripple outward" and positively influence other areas. In the field of play therapy, this hypothesis appears to have been substantiated.

The rationale for using child-centered play therapy approaches with language-impaired children is well supported by the professional literature. Not only has play therapy been successful in decreasing anxiety (Bouillion, 1974), in increasing the expression of feelings 
(Irwin, 1974), and in promoting a "more adequate flow of feelings" (Smathers \& Tirnauer, 1959) in children with speech difficulties, but it has also been documented to improve speech-impaired children's interpersonal relationships (Adams, 1999; Buschbacher, 1999; Dupont, Landsman, \& Valentine, 1953; Jackson, 1950; Sokoloff, 1959; Wakaba, 1983;). Furthermore, interventions that utilize play therapy have been shown to improve specific language impairments such as stuttering (Andronico \& Blake, 1971; Wakaba, 1983), general articulation (Kupperman, 1980), vocabulary (Sokoloff, 1959), fluency (Bouillion, 1974), and expressive language (Irwin, 1974).

However, despite the extensive documentary evidence that play therapy is an effective means of intervention with speech impaired children, solid, well-designed, and specific research conducted in this area is lacking. Of the 18 published research studies relating directly to playbased interventions and language development, only 7 employed child-centered play therapy according to the Axline (1947) principles. Of these seven, only three utilized group methods. Ten of the 18 studies utilized experimental design, yet only 8 used objective testing instruments: 5 studies used only articulation assessment instruments, 1 used only a behavior rating scale, 1 used only a self-efficacy scale, and only 1 study out of all 18 studies conducted utilized both a language assessment instrument and a social maturity scale. It is most important to note that no studies to date have employed extended child-centered group play therapy with languageimpaired children and also assessed its efficacy using objective instruments that measure three critical factors: (1) articulation, receptive, and expressive language, (2) social development, and (3) emotional development.

\section{Statement of the Problem}

The problem with which this investigation was concerned was that of determining the efficacy of child-centered group play therapy with pre-kindergarten and kindergarten children with speech difficulties as an intervention strategy for improving specific speech problems in the areas of articulation, receptive language, and expressive language. In addition, this investigation evaluated the effectiveness of child-centered group play therapy in promoting positive emotional 
growth and improved social relationship skills among pre-kindergarten and kindergarten children with speech difficulties.

\section{Review of Related Literature}

The following review is a synthesis of literature and research related to five major areas: (1) the connection between play and language, (2) the optimal environmental conditions in which language is learned, (3) current trends in speech therapy interventions, (4) specific outcomes related to the use of play therapy with language impaired children, and (5) a rationale for using group play therapy with children with speech difficulties. A summary table of the related research is found in Appendix A

\section{The Connection Between Play and Language}

"The child does not, in the first instance, communicate with his fellow beings in order to share thoughts and reflections; he does so in order to play" (Piaget, 1959, p. 27). Historical literature demonstrates a long-established connection between the development of play behaviors and the acquisition of language. As Formaad (1974, p. xii) stated, "Play is powerfully at work in the growth process of the child and is related most closely to the motivation and exercise of speech.”

The notion that both play and language require symbolic representation is the foundation for two important developmental theories in the field of child development. One, a scale of symbolic development applied to play, was proposed by Piaget (1962), and the other, a scale of symbolic development applied to language, was proposed by Werner and Kaplan (1963).

Piaget (1962) first divided the sequence of children's general play development into three broad categories: (1) practice play, (2) symbolic play, and (3) play with rules. Specifically, symbolic play, which begins approximately between 16 and 20 months of age and continues until approximately age six, progresses through the following general sequence (McCuneNicolich, 1975, p. 50): 
1. Enactive representation - the child shows understanding of object use or meaning by gestures.

2. Symbolic schema - the child pretends at his own usual activities such as eating, sleeping, or grooming.

3. Single schema symbolic play

a. Assimilative - the child has other objects or people take his normal role in pretend activities such as eating, sleeping, grooming.

b. Imitative - the child pretends at activities of other people, such as dogs, trucks, etc.

4. Single schema combinations - the child plays at only one action, such as eating, but expands it to various objects or people, i.e., eating various foods, or feeding dolls.

5. Multi schema combinations - the child plays at several actions, i.e., grooming the doll, feeding it, rocking it, but there are no planned elements, and the sequence is not realistic.

6. Planned single schema symbolic play - activities from level 4 that are planned in advance.

a. Symbolic identification of one object with another, such as a stick for a car.

b. Symbolic identification of the child's body with some other person or object, i.e., pretending to be a cat.

7. Combinations with planned elements - the child plans multi-schema combinations that tend toward realistic scenes and sequences.

Similar to Piaget's symbolic play development scale, Werner and Kaplan (1963) developed a scale of symbolic representation applied to language development. This scale proceeds according to the following general sequence (McCune-Nicolich, 1981, p. 786):

1. Presymbolic schemes - the child performs a conventional gesture in response to a familiar object. 
2. Autosymbolic schemes - the child shows an awareness of the meanings of conventional gestures and uses them playfully only with respect to the child's own body.

3. Decentered symbolic games - the child's schemes become more generalized and distanced from the child's body, and the child uses these gestures with dolls or other objects, remaining limited to one scheme demonstrated at a time.

4. Combinatorial symbolic games - the child begins to combine the gestures into sequences, i.e., the scheme for drinking and the scheme for going to bed can be demonstrated with the doll.

5. Internally directed symbolic games - the child generates mentally the combinatorial symbolic games before their performance, instead of relying on the presence of a particular object.

The work of McCune-Nicolich (1981) indicated that the language abilities demonstrated by children according to the Werner/Kaplan scale coincided in a parallel fashion with the symbolic play abilities demonstrated by children according to the Piaget scale. Her findings showed:

1. During Piaget's symbolic stage 1 (Enactive Representation), children demonstrated imitations of the sounds of the objects used in gesturing, thus a close association of communicative vocalization with action was found.

2. During Piaget's symbolic stage 3 (Single Schema Symbolic Games), children demonstrated use of referential language to describe a category of entities, thus the use of first words and first pretend behaviors outside of self were found to coincide.

3. During Piaget's symbolic stage 4 (Primitive Single Schema Combinations), children demonstrated use of differentiated language, indicating that children differentiate their words to match contexts at the same time they differentiate their play to match various objects. 
4. During Piaget's symbolic stages 5-7 (Combinations and Planned Elements), children demonstrated use of predominantly multi-word combinations, thus the onset time for combinations of words in speech was found to coincide with combinations of symbolic schemas in play.

Significant connections between the levels of symbolic play and the levels of language development have been well documented in the field of language research. McCune-Nicolich (1975), one of the leading authorities on play and language, conducted a longitudinal study of symbolic play and multi-word utterances. Five female subjects, ranging in age from $14-19$ months were observed over a one-year period. Results indicated that children's symbolic play level was a significant $(\mathrm{p}<.03)$ predictor of linguistic behavior. Specifically, all five subjects had achieved symbolic play level 4 (Single Schema Combinations) before the appearance of three or more different multi-word combinations. All five subjects had similarly attained symbolic play level 7 (Combinations and Planned Elements) before multi-word utterances were more numerous than single-word utterances. Finally, the study determined that the number of action-judgements (defined as words used to express perceived relationships between objects in the environment, i.e., "more", "up", etc.) produced by the child in a given play session was also correlated with symbolic play level $(\mathrm{r}=.55)$.

Further evidence supporting the play-language connection was provided in a study conducted by Bloom (1993), which determined that the emergence of children's first words was dependent upon their reaching the developmental level associated with an ability to construct thematic relations between two objects in their play. Similarly, Bloom (1993) found that vocabulary spurts, which occur generally during the age span of 14-20 months, were closely associated with the child's ability to construct specific thematic relations between objects in their play that took into account differences in the particular properties of those objects. Her findings were earlier implied by Bricker and Bricker (1974), who asserted "the importance of learning 
non-linguistic behaviors found in object-specific play that are preliminary to certain language behaviors" (p. 402).

In her development and use of the Symbolic Play Scale, an instrument used for assessing children's levels of language development, Westby (1980) found, “In no evaluation has a child's meaningful use of language been above his/her symbolic play level” (p. 161). Scherer (1997) conducted a study of six children with cleft lip/palate at 20, 24, and 30 months of age during 30 minute play sessions. Outcomes revealed that children who produced more symbolic play gestures, operationally defined as the number of play gestures produced in response to a placeholder object as opposed to a real object, also produced significantly more vocabulary words. That is, a child who produced 9 symbolic play gestures in 30 minutes also produced 40 different vocabulary words, as compared with a child who produced only 3 symbolic play gestures in 30 minutes and produced only 6 different vocabulary words. Additionally, Scherer (1997) discovered that mean length of utterance (MLU) significantly coincided with length of symbolic play sequences.

Ungerer and Sigman (1984) compared the developmental play level of autistic children between the ages of 19 and 21 months with the developmental play level of children without handicaps. They determined that of the 16 non-verbal autistic children studied, not one had demonstrated true symbolic play. Van Berckelaer-Onnes (1994) referred to several studies that confirm autistic children rarely engage in symbolic play (Bender, 1956; Rutter, 1974). Wing, Gould, Yeats, and Brierly (1977) similarly found that among the language-disordered children in their study, no child with a verbal comprehension age of less than 20 months had developed symbolic play. Therefore, the absence of the attainment of symbolic play would appear to indicate a substantial impairment in language development.

Rescorla and Goossens (1992) studied the symbolic play development of 40 toddlers between the ages of 24 and 26 months with expressive specific language impairment (SLI-E). Their results indicated that the "2 year-olds with expressive SLI engaged in a significantly higher 
frequency of manipulation and handling of toys [non-symbolic play]...than did the normallanguage subjects $[t(38)=-2.55, \mathrm{p}<.05]$ " $(\mathrm{p} .1295)$. Furthermore, the normal language children in the study exhibited significantly $(\mathrm{p}<.01)$ more sequencing and symbolism in their play than did the SLI-E children. A study by Mogford (1985) utilized the world technique (a play therapy activity in which children are presented with a variety of miniatures and asked to build a "world") with 20 language disordered boys ages five to six years and found that the language disordered children, as compared to the control group, made less complex worlds. She concluded, "It is argued that unless children can understand and identify the relations between people, objects, and events, they cannot use sentence structures which express these relationships in linguistic terms" (p. 257).

Substantial evidence exists to support the opinion that "play is an essential precursor to language" (Martin, 1981, p. 49) and that "a child who shows impairment of his ability to play almost always has difficulty in learning to talk" (p.49). Indeed, Vygotsky (1933) has termed symbolic play the "critical pivot" in the development of the ability to use spoken words to represent objects. Of play, Hubbell (1981) wrote, “The symbolic quality, combining relevant sequences of behavior, its autotelic nature, and its sheltering atmosphere makes it a highly desirable format for language learning” (p. 257). Hence, as McConkey (1976) asserted, "By helping a child's imaginative play we can lay the foundations of his language development" (p. 13).

\section{Optimal Environmental Conditions for Language Learning}

Given the strong connection between play and language, the use of play therapy with speech-impaired children is supported by conclusions regarding the overall optimal conditions that promote language development as determined by research in the field. Not surprisingly, such studies have concluded that children acquire language most effectively in natural contexts that are supportive, child-centered, enjoyable, and ones in which adults and children are jointly 
focused on objects of immediate interest (Bloom, 1993; Ervin-Tripp, 1991; Hubbell, 1981; Kovarsky, 1990; Mogford-Bevan, 1994).

Hubbell (1981) identified five significant environmental factors that are present in all natural environments in which children learn language:

1. The child feels free to explore,

2. The child receives immediate feedback regarding the consequences of behavior,

3. The child determines the rate at which events happen within the environment,

4. The child is permitted to make full use of his capacity for discovering relations of various kinds, and

5. The child is likely to make a series of interconnected discoveries about the physical, cultural, or social world (p. 211).

This description of a child-centered, non-restrictive, responsive, and insightful environment is echoed by other language specialists, most notably, Ervin-Tripp (1991), who delineated three similar conditions of language learning: (1) exchanges must be salient and motivating, (2) input should be short, comprehensible, and understood within the context of the child's natural environment, and (3) these one-on-one exchanges should be "delicately tuned to the learner's knowledge and interest" (p. 85).

Closely mirroring these optimal environmental conditions are the eight basic environmental principles outlined in Axline's (1969) approach to play therapy:

1. The therapist must develop a warm, friendly relationship with the child in which good rapport is established as soon as possible.

2. The therapist accepts the child as is.

3. The therapist establishes a feeling of permissiveness in the relationship so the child feels free to express his/her feelings completely. 
4. The therapist is alert to recognize the feelings the child is expressing and reflects those feelings back to him/her in such a manner that he/she gains insight into his/her behavior.

5. The therapist maintains a deep respect for the child's ability to solve his/her own problems if given an opportunity to do so. The responsibility to make choices and institute change is the child's.

6. The therapist does not attempt to direct the child's actions or conversation in any manner. The child leads the way; the therapist follows.

7. The therapist does not attempt to hurry therapy along. It is a gradual process and is recognized as such by the therapist.

8. The therapist establishes only those limitations that are necessary to anchor therapy to the world of reality and to make the child aware of his/her responsibility in the relationship (pp. 73-74).

Hence, the environment created within the play therapy relationship contains all the necessary elements of optimal language learning - freedom to explore, acceptance, childdetermined pacing, and feedback that is short, immediate, directed towards objects of interest to the child, and occurs within the child's natural environment. Indeed, many language specialists have asserted that the combination of joint reference, genuine interest, and natural contexts are fundamental elements of language acquisition (Hubbell, 1981, p. 193; Benjamin, 1984, p. 10; Cogher, 1999, p. 10).

Furthermore, if children are to be successful with language acquisition, they must be provided with an atmosphere in which they can be "emotionally and intellectually involved" (Mogford-Bevan, 1994, p. 159). Play therapy maintains a consistent focus on the feelings of the child through the use of specifically selected toys, which also stimulates the child's cognitive abilities required for symbolic play. In addition, children must participate in an "enjoyable, communicative framework" (p.160) in order for successful language acquisition to occur. Play 
is the natural medium of communication for children and is an enjoyable end in itself (Benjamin, 1984, p. 10). Bloom (1978) suggested that the language-learning environment "not be limited to the variety of contextual situations that can occur" (p. 555). Play therapy rooms are fully equipped with toys designed for expressing a wide range of contextual situations - aggression, fear, regressive play, nurturance, power, control, relationship building, and domestic/family situations. Sufficient support seems to exist for advocating play-based speech interventions that take into account these conducive environmental factors.

In addition to such positive conditions, language scholars have also noted factors that negatively influence successful language development. Kovarsky (1990) found that "children... appear quite sensitive to the regulatory role often assumed by clinicians" (p. 38), and because most adult-controlled processes are so far removed from how conversations proceed under natural circumstances, a negative impact upon children's ability to generalize language skills often results. Hubbell (1981) and Ervin-Tripp (1991) agreed: “if children interact only... in controlled didactic contexts, they are constantly in a subordinate situation with respect to both knowledge and power" (p. 95). As well, Westby (1980), citing a study by Nelson (1973), stated that "directive, adult-led teaching has been shown actually to retard, rather than facilitate, progress" (p. 161).

Therefore, speech interventions that consider the negative impacts of clinician-controlled approaches and, instead, focus on creating "the kind of environmental support for exploration and coping behaviors that accompanies early...language development” (Seitz, 1974, p. 303) would appear to have a positive impact upon children's language acquisition and development. Ritter (1985) agreed: "play will heighten interest, attention, and voluntary cooperation..... There should be no single expectation of a child's performance since any number of responses may not only be appropriate, but creative and revealing of thought and language" (p. 19). Benjamin (1984) also asserted that play-based interventions most effectively achieve "the clinical goals of stimulating increased quantity of spontaneous language output, facilitating the use of language in 
interpersonal communication, and allowing the client to experience different speaker roles" (p. 11). According to Reissman (1966, as cited in Irwin, 1972, p. 132), "asking the disadvantaged child to suppress the language he brings to the learning situation is equivalent to demanding that he suppress his identity" (p. 132)

Perhaps the writing of Leland (1982) best describes the role of play in creating an optimal environment for language learning:

We find that our first necessity is to try to discover what it is that the child can do, and in the area of play therapy, what types of play activities are most responsive - where, in other words, are the "hills" or areas of strength, because it is absolutely necessary that the child be approached in terms of the strengths, recognizing that the weaknesses, or "valleys" are there because of specific errors in development. Emphasis on the "valleys" would only increase the frustrations, further disturb the personality development and make therapy both a painful and probably unsuccessful task. It is our experience then that if these "hills" are properly developed, the "valleys" have a tendency to grow... and the therapy is able to move forward" (p. 5-7).

\section{Current Trends and Outcomes in Speech Therapy Interventions}

Recently, the field of speech therapy appears to have recognized the strong connection between play and language as well as the environmental considerations discussed above. As a result, speech therapy interventions have gone through a transition from rigid, clinical, and directive approaches to more natural, contextual, and play-based approaches.

Holm and Dodd (1999) documented this trend in their description of speech therapy in England. Speech therapy approaches were divided into three separate categories: (1) phonological contrast therapy, which is directive, problem-targeted, and one in which materials are chosen by the therapist, (2) core vocabulary therapy, which is directive, but materials are chosen by the child, and (3) whole language therapy, in which skills are introduced in the context of a child's natural learning environment - play. Wade and Haynes (1986) described a continuum of American speech therapy strategies, ranging from structured (trainer-directed, behavioral, "drill-made" approaches), to hybrid (approaches that allow the child to exhibit interest in a variety of stimuli while being presented with cues and prompts from the therapist), 
to naturalistic (therapist follows the child's lead and works with the language the child has produced in their natural environment - play).

Speech assessment tools also reflect this trend toward non-directive, play-based strategies. Klein and Moses (1999) have classified three types of assessment instruments: (1) standardized, norm-referenced instruments, (2) case history data taken from people within the child's environment, and (3) non-standard instruments that measure language generated through spontaneous play interactions. McCormick and Scheifulbusch (1984) utilized play as a language assessment tool by determining children's interpersonal verbal and non-verbal communication skills through parent interviews after the parents had participated in informal observations of their child's play. Westby (1980) developed a language assessment instrument that relies solely on clinical play observations - the Symbolic Play Scale - which uses a child's demonstrated developmental level of play as an indicator of the child's developmental level of language.

Research supports the efficacy of specific language intervention models that utilize play-based strategies as a means of improving specific language deficits. Results from one such model, implemented by Broen (1990), indicated that children improved significantly $(\mathrm{p}<.012)$ on phonological errors after 17 play sessions with their mothers. Donahue-Kilburg (1992) cited a case study in which the Natural Incidental Language Treatment model of intervention was used. In this play-based model, "joint attention of the child and adult to an object or event is established by having the adult follow the child's lead.... The adult simply attends to what the child is attending to and provides language input on that topic" (p. 240). For a three year-old language-delayed boy, the outcome showed an increase in the percentage of intelligible utterances from 40 to $90.4 \%$. Repeated syllables decreased from 37.9 to $10.2 \%$, and mean length of utterance increased from 1.4 to 3.29 morphemes per utterance.

Strong documentation is also found for the Ecology of Communication model of intervention designed by MacDonald (1989). This model trains parents "to understand and personally integrate a series of strategies into direct and spontaneous contacts with their 
children" (p. 301) through the medium of play. Results of the research conducted on this model indicated that the mean score on specific language items (Intentional Communication, Making Self Understood, Following Grammatical Rules, Communicating Verbally, and Using a Variety of Vocabulary) increased from 12.43 to 22.14 , a significant difference at the .001 level. In addition, Rossetti (1996) cited a study conducted by Girolometto in 1986 using the Hanen Approach for speech intervention. He found that after play sessions conducted with trained mothers, the children in his study were more contingently responsive, initiated more topics, and ignored mothers less often than did the control group.

Rustin (1996) obtained noteworthy results with Interaction Therapy, a speech intervention program designed to develop children's language skills within the context of play interactions. In a case study of a three year-old dysfluent boy, outcomes showed that after six weeks of special play times, "the periods of dysfluency tended to be shorter in duration and with increasingly longer intervals in-between" (p. 113). Levenstien (1985) noted that after implementing the Mother-Child Home Program, a model in which interactive skills are modeled for mothers conducting home play sessions with their children, the mothers' general verbal responsiveness (as learned from the trained therapist) significantly predicted the child's level of self-confidence as a communicator.

Ample evidence appears to exist that the current trend in speech therapy - a shift towards more child-centered, play-based intervention methods - substantiates the hypothesis that childcentered play therapy can significantly impact the language development of speech-impaired children. Too often, play has been used by speech therapists "as a diversion for a job well done rather than an intrinsic part of the learning" (Ritter, 1985, p. 4). Hubbell (1981) entreated: Instead of designing a strategy for teaching language, let us think about designing a human relationship context that might maximize the chances of children's developing language through their own active learning strategies. I would argue, then, that the most 
powerful intervention strategies for working with language disordered children will be those that help the child develop language in relationship contexts" (p. 102-103).

\section{Specific Outcomes of Play Therapy Interventions}

The play therapy relationship, as described by Landreth (2002), is “...a safe relationship for the child to fully express and explore self (feelings, thoughts, experiences, and behaviors) through the child's natural medium of communication, play" (p. 14). Research indicates that play therapy experiences are helpful to children with a wide range of problems, including speech difficulties (Ray et al., 2001). Axline (1947, p. 59) stated, "Speech problems, such as stammering, stuttering, baby talk, repetitious language, and garbled language [also] seem to be corrected by play therapy."

Outcomes related to specific speech disorders: As early as 1946, Reymert conducted research in which a seven-year-old child with a stuttering speech defect was able to overcome his disorder as a result of two weeks of non-directive play therapy. In 1953, Dupont, Landsman, and Valentine found that an eight-year-old boy with garbled language decreased his omission of phonetic sounds from six to zero after 41 child-centered play therapy sessions, without direct speech instruction. James (1977) also included reference to an unpublished doctoral dissertation by Homefield (1959), which found that children who stutter spoke more fluently during roleplay than during regular speech interactions.

Landreth (2002) cited a study conducted by Sokoloff in 1959 that indicated statistically significant improvements $(\mathrm{p}<.01)$ in communication abilities (articulation, intelligibility, voice, vocabulary, and language level) among 12 cerebral-palsied children who participated in 30 group play therapy sessions. Smathers and Tirnauer (1959) found concomitant improvements in the speech of four eight-year-old boys with stuttering and unintelligible speech through the use of group theraplay.

Researchers conducted few studies during the 1960's on play therapy with children with speech difficulties, but increased the pursuit of such studies during the 1970's. Andronico and 
Blake (1971) discovered that in the course of filial therapy, one mother noted a reduction of stuttering by her child in play sessions, and this reduction was eventually generalized outside the play sessions. Goraj (1974) reported success utilizing play therapy techniques with stutterers in her "crisis intervention" approach to therapy. Bouillion (1974) researched 10 speech delayed children ages three to six and found that those children receiving 70 non-directive group play therapy sessions achieved significantly higher scores in fluency and articulation than did children in motor training, direct speech therapy, or the control group.

In addition, Irwin (1974) conducted a study of pre-school children aged three to six with cleft palates. In 37 sessions of group play therapy, she discovered significant improvements in children's communication skills. McConkey (1976) conducted a case study of a 3 1/2 year-old girl who used mostly single-word utterances in her expressive language and reported that after 20 play sessions, the mean number of two-word utterances increased from 0 to 9 . In addition, her spontaneous language increased from $60 \%$ of her total utterances to $88 \%$.

The subsequent decade also proved to be rich in play therapy research regarding speech difficulties. In 1980, Kupperman, Bligh, and Goodban studied six children aged three to four with speech difficulties. Over the course of six weeks in theraplay sessions, the overall reduction in articulation error items was 10.8. Wakaba (1983) demonstrated increased speech production and decreased occurrences of stuttering with three Japanese boys aged four to five in 21 sessions of non-directive group play therapy. Wade (1986) determined that child-directed play was not statistically less effective in the production of spontaneous language than was adult-directed play (38.2 spontaneous responses in child-directed vs. 42.5 in adult-directed) for a group of nine language impaired children aged two to three years. Brooks and Benjamin (1989) conducted 13 sessions of role-playing with three children aged four to six with delays in the development of expressive language skills. Results showed that improvement in the production of two grammatical forms, auxiliary is and auxiliary are, improved from $10 \%$ and $0 \%$, 
respectively, to $95 \%$ and $100 \%$, respectively, after eight weeks. Follow-up studies ten months later showed that these changes remained stable.

Outcomes regarding emotional factors: In Irwin's 1974 study, children with cleft palates were increasingly able to express personal anxiety and fear by the $16^{\text {th }}$ play therapy session. Irwin concluded that when a child is engrossed in play, past hurt and fear might be more easily recalled. Bouillion (1974) discovered decreased anxiety in speech-delayed children who participated in group play therapy, and Smathers and Tirnauer (1959) also concluded that children in theraplay experienced a more adequate flow of feelings. Johnson (1997, p. 32) reported three boys with expressive language delays were better able to "express a range of feelings, including anger, sadness, and helplessness" (p. 33) after just six non-directive play therapy sessions.

Smith (2002) found statistically and practically significant decreases in withdrawal behaviors among deaf and hard of hearing pre-school children who had experienced childcentered play therapy sessions with teachers trained in filial therapy. Smith (2002) described such children as experiencing social delays and isolation due in part to their delay in language development. His clinical observations also included evidence of an increase in conversations initiated by the children in the experimental group.

Only five existing studies have measured the effect of play therapy as it relates to the emotional development of children with speech difficulties. Therefore, it would appear that further supporting research in this area is warranted.

Outcomes regarding social factors: Dupont, Landsman, and Valentine (1953) cited a study conducted by Werner in 1945 in which the researcher found that children in therapy usually improved in social and interpersonal relations. Landreth (2002) described a case study by Jackson (1950) involving a $31 / 2$ year-old boy with regressed speech. After 41 play therapy sessions, the researcher noted improved social skills, as well as an increase in free verbal exchanges between the child and the therapist. Sokoloff's 1959 study yielded statistically 
significant improvement $(\mathrm{p}<.05)$ in scores on the Social Maturity Scale among children with cerebral palsy who had participated in group play therapy.

Orphan (1961) reported that a play therapy program implemented with children with handicaps at a Rhode Island school resulted in increased opportunities for socialization, group identification, and approval. He also noted less withdrawing behaviors. Irwin (1974) reported more direct verbal interaction between children by the $16^{\text {th }}$ play therapy session. In Wakaba's 1983 study, children with stuttering achieved higher scores on the Social Maturity Scale; average scores increased from 6.05 to 8.06 . In particular, the boys in the study had greater contact with each other and with peers at school as play therapy progressed.

Donahue and Hartas (1999) referenced a study conducted by Evans and Ellis (1992) in which verbally withdrawn children made more simple requests of others for information and attention during free play. Buschbacher (1999) reported that two three-year-old boys with communication disabilities saw themselves as valuable, contributory members of their peer culture (as did their peers without disabilities) at the end of a seven month period of dramatic play sessions. Adams (1999) found an increase in prosocial behavior after semi-structured play sessions among three dyads of speech-delayed children aged three and four, and their older siblings.

A thorough review of the professional literature revealed no studies in which play therapy did not foster speech improvement. Given the above research, significant evidence clearly exists that play therapy not only is an effective means of promoting improvement in specific speech disorders but also is an effective means of supporting positive emotional and social development in children with speech difficulties.

\section{A Rationale for Group Play Therapy}

Smith and Smith (1999) asserted that the "need to engage other children in play seems to be innate and universal.... It is part of the human socialization process to want to be with other children in play, even if their play skills at times are underdeveloped or troublesome" (p. 236). It 
is no surprise, then, that nine of the research and case studies described above utilized group play therapy methods. Indeed, group play therapy methods have been linked to improvements in social acceptance (Bevins, 1970; Pelham, 1972; Thombs and Muro, 1973), self-concept (Crow, 1971; House, 1971; Hume, 1967; Mann, 1968), and linguistic abilities (Irwin, 1972; Moulin, 1970).

Landreth and Sweeney (1999, p. 53) identified numerous facilitating dimensions of childcentered group play therapy that makes it a desirable, appropriate method of intervention for children with speech difficulties:

- It is less threatening for the child to enter the new experience in the company of two or three other children.

- It facilitates the establishment of desired relationships.

- It diminishes tension and stimulates activity.

- It increases spontaneity.

- It provides peer reactions from which children can re-evaluate their behavior.

- It ties the therapy to the child's real world.

- It provides models and opportunities for vicarious and direct learning.

According to Bratton (personal communication, 2001), an additional dimension is the safety of the group play therapy experience which provides children with the opportunity to develop, practice, and master new behaviors/skills. This is a vital element for language impaired children who require "a buffer from the usual unpleasant, negative consequences of dysfunctional language" (Cogher, 1999, p. 9) in order to improve their skills.

It would appear, then, that the child-centered group play therapy setting would provide such children with an encouraging environment - one in which they are able to imitate and learn language from peers, experience acceptance and respect in their attempt to master new linguistic skills through trial and error or repetitive play, develop associations between the linguistic 
patterns and relational concepts found in symbolic play, and engage in dramatic play behaviors with peers that allow for experimentation with new language structures and speaker roles in a non-threatening setting. Perhaps most importantly, the group provides a "microcosm of the child's everyday world" (Sweeny \& Homeyer, 1999, p. 3) and thus is optimal for generalizing newly learned linguistic skills into the child's everyday language.

A thorough review of the research in the field of group play therapy yields ample support for its use with speech impaired children. In addition to the specific language-related results from the group play therapy studies mentioned above (Adams, 1999; Bouillion, 1973;

Buschbacher, 1999; Homefield, 1959; Irwin, 1974; Smathers \& Tirnauer, 1959; Sokoloff, 1959; Wakaba, 1983), results from a study conducted by Moulin (1970) indicated that first, second, and third grade children who participated in 12 child-centered group play therapy sessions significantly $(\mathrm{p}<.0005)$ improved their scores on the Illinios Test of Psycholinguistic Abilities, as compared with the control group. Children in the experimental group improved their scores from 163.00 to 191.91 , while the control group scores increased from 167.83 to only 169.41 over the 12 weeks. Moulin concluded that child-centered group play therapy "was effective in significantly increasing meaningful language usage" (p. 93).

George, Braun, and Walker (1982) conducted group play sessions with 38 disadvantaged pre-school children and found that after 56 sessions, scores on the Associative Vocabulary subscale of the Cooperative Preschool Inventory improved from 53\% to $100 \%$. Two case studies further illustrate the effectiveness of group play therapy in facilitating language. The first is a case study conducted by Barlow, Strother, and Landreth (1986) of a five year-old elective mute child. After 9 months and 36 sessions, the child "became more verbal and more actively participated in her world. She even read a Christmas story over the loudspeaker at school" (p. 48). The second case study (Burlingham, 1938) involved a socially isolated girl with regressed speech. After 2.5 years of group play therapy, "her speech was greatly improved and she was friendly and outgoing in her relationships with children" (p. 634). 
Of noteworthy importance is a related study conducted by Trostle (1988) in which 12 three to six year-old bilingual Puerto Rican boys participated in 10 child-centered group play therapy sessions. Results indicated that these children showed significant improvement in their ability to demonstrate higher developmental levels of symbolic play as compared to the control group. This study, designed to examine the results of an earlier study by Reif and Stollak (1972), confirmed their findings that children who receive play therapy increased in their symbolic play levels. Therefore, this finding indicates that group play therapy, in addition to improving specific speech deficits, also improves symbolic play development - a critical link in children's language acquisition.

Outcomes regarding emotional factors also lend support for child-centered group play therapy as a potentially effective intervention for children with speech difficulties. Fleming and Snyder (1947) determined that after group play therapy, children in the experimental group scored significantly higher in personal feelings toward self than did the control group. Similarly, Pelham (1971) found that after eight non-directive group play therapy sessions, nine kindergarten students "were better able to differentiate more aspects of their self-concept" (p. 3798). Cowden (1992) also determined that child-centered group play therapy promoted a "progression toward higher self concept" after eight sessions. House (1970) found that second grade children who participated in 12 non-directive group play therapy sessions "showed a significantly greater increase in self-concept scores than those subjects in the control group" (p. 2684). A case study by DeMaria and Cowden (1992) showed that after 10 child-centered group play therapy sessions, two girls, aged six and seven, were able to reduce significantly their anxiety and fearfulness.

Another important aspect improved by group play therapy is that of social interaction. Outcomes in this area show that child-centered group play therapy contributes to children's positive social development. George, Braun, and Walker (1982), in addition to their findings related to associative vocabulary development, also found that disadvantaged pre-school children 
significantly improved their scores on the Social Responsiveness subscale of the Cooperative Pre-school Inventory (from 74\% to $100 \%$ after 56 sessions). Fleming and Snyder (1947) determined that after 12 weeks of non-directive group play therapy, three girls, aged eight to nine, made marked improvement in "sociometric acceptance" $(\mathrm{p}<.01)$.

Boulanger and Langevin (1992) conducted a study with an experimental group of five five-year-old boys who exhibited "problems socializing with peers" (p. 229). Results showed that after 14 group play therapy sessions, significant improvement was obtained on the following subscales of the Direct Observation Form: (1) Withdrawn/Inattentive, (2) Nervousness (3) Demanding Attention, and (4) Aggressiveness. The five-year-old boys in this study decreased their anti-social behavior and increased such pro-social behaviors as "offering help, initiating social contacts, expressing one's gratitude or admiration, and using humour to initiate or reinforce social interaction" (p. 233).

In addition to outcomes regarding social factors previously examined in the research by Sokoloff (1959), Irwin (1974), and Wakaba (1983), Schiffer (1965) found that group play therapy stabilizes peer relations over time. Furthermore, Boyd (1944) noted "more cooperative attitudes," "increased ability to work together," and a "decrease in destructiveness and combativeness" (p. 17-18) after implementing group play. A case study presented by Johnson (1988) showed that after experiencing play group therapy, an eight year-old boy initiated more play with peers and became less isolated and withdrawn. She also indicated similar improvements in a six-year boy, who was able to decrease his aggressive social interactions.

Child-centered group play therapy appears to be a well-established and successful means of intervention for children with speech difficulties. The distinctive characteristics of group play therapy create a valuable dynamic that facilitates linguistic, emotional, and social growth.

\section{Summary}

Children with speech difficulties represent the second largest population of school children requiring specialized services in our nation (America's Children, 1999). Research has 
established two significant characteristics of language-impaired children that practitioners must take into account when designing intervention strategies: (1) these children experience emotional problems such as anxiety, low self-esteem, and frustration (Audet, 1990; Baker, 1992;

McGregor, 1993), and (2) these children experience difficulty in social interactions (Bitler, 1976; Donahue \& Hartas, 1999; Mogford-Bevan, 1994). Speech difficulties are not an isolated problem; they impact the whole being of the child. A speech intervention strategy that addresses the whole child would therefore appear to be a more effective approach than an approach that is compartmentalized, narrow, and isolated in focus.

The field of speech and language development offers scientific support for the contention that a holistic, play-based approach to speech intervention yields positive results. Play-based approaches have been shown to be successful in various research studies (Broen, 1990; MacDonald, 1989; Rossetti, 1996; Rustin, 1996). These outcomes reflect the long established connection between the development of play and the development of language. Based on their research, language specialists have indicated that symbolic play is a possible precursor to successful language acquisition (McCune-Nicolich, 1975). The literature also suggests that play provides (1) opportunities for joint reference, (2) experiences that are of genuine interest to the child, and (3) a natural context for expression - the three most important environmental conditions for optimal language learning.

Furthermore, the field of play therapy lends additional support for this hypothesis in the outcomes of research-based studies that show the child-centered play therapy approach results in improved speech (Bouillion, 1973; Irwin, 1974; Moulin, 1970; Sokoloff, 1959; Wakaba, 1983), enhanced self-concept (Cowden, 1992; Fleming \& Snyder, 1947; Pelham, 1971), and greater positive social interaction (Fleming \& Snyder, 1947; George, Braun, \& Walker, 1982; Schiffer, 1965). More specifically, the medium of group play therapy has been shown to address linguistic, social, and emotional needs of young children (Bevins, 1970; House, 1971; Irwin, 1972; Moulin, 1970). 
Studies conducted in the field of play therapy have thus far looked only at isolated outcomes: language growth, social growth, or emotional growth. No studies have yet been published that test the efficacy of the group play therapy approach over time and assess its holistic impact upon the linguistic, emotional, and social areas of development in children with speech difficulties. 


\section{CHAPTER II}

\section{METHODS AND PROCEDURES}

This chapter presents the methods and procedures utilized for this study. Included in this chapter are the definition of terms, a list of hypotheses, descriptions of the instruments utilized for data collection, a discussion of the selection of participants, specific methods of data collection, a description of the treatment, and an explanation of the data analysis procedures.

\section{Definition of Terms}

Anxiety describes the level of emotional discomfort a child feels as a result of his or her speech difficulty, and was operationally defined for the purposes of this study as the child's score on the "Anxiety" subscale of the Burks' Behavior Rating Scale (BBRS) (Burks, 1977).

Articulation refers to the manner in which sounds are formed. These can be characterized by the substitution of one sound for another, or the omission or distortion of certain sounds. For the purposes of this study, articulation was operationally defined as the child's score on the Goldman Fristoe Test of Articulation (GFTA) (Goldman, 1986).

Child-centered group play therapy, based on the Landreth (2002, p. 16) definition of play therapy, was defined as follows:

Child-centered group play therapy is a dynamic, interpersonal relationship between two to three children and a therapist trained in play therapy procedures who provides selected play materials and facilitates the development of safe relationships among group members so that the children are able to fully express and explore self (feelings, thoughts, experiences, and behaviors) through play, the children's natural medium of communication, for optimal growth and development.

Children with speech difficulties was defined in this study as the randomly selected sample from 45 pre-kindergarten or kindergarten students, aged 4 to 6 , who qualified for speech therapy services administered at a public primary school in a rural area of North Texas. 
Child's sense of identity describes the inner sense of understanding, comfort, and acceptance of self that the child possesses. For the purposes of this study, sense of identity was operationally defined as the child's score on the "Sense of Identity" subscale of the BBRS.

Delayed speech was defined as a communication disorder in which certain expected levels of development in comprehension, syntax, and articulation have not yet been reached.

Expressive language, the amount of comprehensible vocabulary and syntax a child is able to produce vocally, was operationally defined for the purposes of this study as the child's score on the "Expressive Language" subscale of the Clinical Evaluation of Language Fundamentals Third Edition (CELF -3) (Semel et al., 1996).

Fluency refers to the flow of speech. Disturbances in fluency most often take the form of stuttering (also called dysfluency).

Receptive language, the amount of comprehensible vocabulary a child hears and understands, was operationally defined for the purposes of this study as the child's score on the Peabody Picture Vocabulary Test - Revised (PPVT-R) (Dunn, 1981) and the child's score on the "Receptive Language" subscale of the CELF-3.

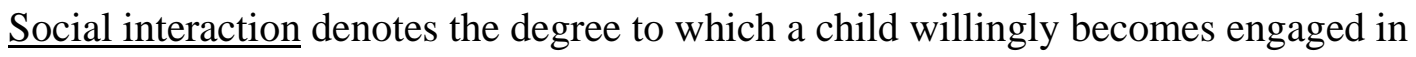
conversation, work, or play with peers in a socially acceptable manner. Social interaction was operationally defined for the purposes of this study as the child's score on the "Social Conformity" subscale of the BBRS.

$\underline{\text { Speech difficulties }}$ refers to a wide variety of problems in a child's ability to communicate, including articulation, voice disorders, fluency problems, and delays in speech and/or language.

$\underline{\text { Syntax }}$ refers to the order of words in a sentence.

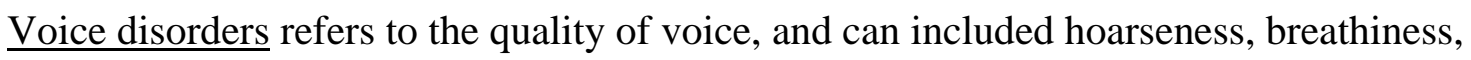
or sudden breaks in loudness or pitch. 
Withdrawal behavior describes the tendency of a child to be purposely self-isolating and unwilling to respond emotionally in social contexts involving peer groups. Withdrawal behavior was operationally defined for the purposes of this study as the child's score on the "Withdrawal" subscale of the BBRS.

\section{Hypotheses}

To carry out the purpose of the this study, the following hypotheses were formulated:

(1) The experimental group children will attain a significantly higher mean total score on the Goldman Fristoe Test of Articulation post-test than will the comparison group children.

(2) The experimental group children will attain a significantly higher mean total score on the Peabody Picture Vocabulary Test-Revised post-test than will the comparison group children.

(3) The experimental group children will attain a significantly higher mean score on the "Receptive Language" subscale of the Clinical Evaluation of Language Fundamentals Third Edition (CELF-3) post-test than will the comparison group children.

(4) The experimental group children will attain a significantly higher mean score on the "Expressive Language" subscale of the CELF-3 post-test than will the comparison group children.

(5) The experimental group children will attain a significantly lower mean score on the "Anxiety" subscale of the Burk's Behavior Rating Scale (BBRS) post-test as rated by their teachers than will the comparison group children.

(6) The experimental group children will attain a significantly lower mean score on the "Anxiety" subscale of the Burk's Behavior Rating Scale (BBRS) post-test as rated by their parents than will the comparison group children.

(7) The experimental group children will attain a significantly lower mean score on the "Sense of Identity" subscale of the BBRS post-test as rated by their teachers than will the comparison group children. 
(8) The experimental group children will attain a significantly lower mean score on the "Sense of Identity" subscale of the BBRS post-test as rated by their parents than will the comparison group children.

(9) The experimental group children will attain a significantly lower mean score on the "Withdrawal" subscale of the BBRS post-test as rated by their teachers than will the comparison group children.

(10) The experimental group children will attain a significantly lower mean score on the "Withdrawal" subscale of the BBRS post-test as rated by their parents than will the comparison group children.

(11) The experimental group children will attain a significantly lower mean score on the "Social Conformity" subscale of the BBRS post-test as rated by their teachers than will the comparison group children.

(12) The experimental group children will attain a significantly lower mean score on the "Social Conformity" subscale of the BBRS post-test as rated by their parents than will the comparison group children

\section{Instruments}

\section{Goldman Fristoe Test of Articulation}

The Goldman Fristoe Test of Articulation (GFTA) was first developed in 1969 by Ronald Goldman and Macalyne Fristoe. The GFTA was revised in 1972 and again in 1986. It is an individually administered test designed to provide a "systematic means of assessing an individual's articulation of the consonant sounds." Variables measured by the instrument are: (1) sounds in words, (2) sounds in sentences, and (3) stimulability. Normative data was recently derived from data collected by Khan and Lewis (1986) from 852 children, ages 2-6, representing several ethnic groups throughout the United States.

Mowrer (1986) reported test-retest reliability of the GFTA, conducted by eight experienced speech pathologists with 37 children ages $4-8$. Results showed that an overall 
median agreement of $95 \%$ was obtained, the lowest being $70 \%$ median agreement for the Sounds in Sentences subscale. Interrater reliability between six judges listening to tape recordings of the subjects was established at $92 \%$.

Content validity was established by obtaining samples of sounds in three positions of a word, plus in a few clusters. The authors made no attempt to establish predictive or construct validity. The authors mentioned that the scores from the 37 subjects who were given the Sounds in Words subtest and Sounds in Sentences subtest were compared. The low percent of agreement indicated these tests measure different aspects of articulation.

Mowrer (1986) described the GFTA as a useful test that "provides a fairly complete picture of a child's articulation skills. This is true not only for sounds in three positions, but also for sounds produced in context." In addition, the recommended use of the GFTA is for speech pathologists wishing to compare a child's articulation ability with the performance of other children of similar ages who have taken this test.

Peabody Picture Vocabulary Test-Revised

The Peabody Picture Vocabulary Test - Revised (PPVT-R) was developed by Dunn, Dunn, Robertson, and Eisenberg in 1959. The PPVT-R was revised in 1981. The purpose of this instrument is to "measure an individual's receptive (hearing) vocabulary for Standard American English and provide a quick estimate of verbal ability or scholastic aptitude." This is an individually administered test that yields a total score only. The PPVT-R contains 350 items in which examinees are asked to indicate which of four pictures presented on a carousel-mounted plate corresponds to a stimulus word read aloud by the examiner. Normative data was gathered from 4,200 children nationwide, representing the overall population of the United States.

According to the test manual, internal consistency values using split-half procedures were .61 to .88 , and alternate form reliability values were .71 to .91 . These values have been confirmed by subsequent independent studies. Correlation coefficients obtained from comparing 
the PPVT-R to the Wechsler Intelligence Scale and the Stanford-Binet intelligence test scores were .40 to .60 .

Content validity was supported by selection of the vocabulary items on the basis of vocabulary searches and cross-referencing with age and grade level vocabulary lists. Construct validity was supported by gradual increases over age in the percentage of subjects who responded correctly to an item. Concurrent validity was established against the PPVT-R. Coefficients of concurrence ranged from .53 to .87 .

Wiig (1981) described the PPVT-R as an "up-to-date, well standardized, norm-referenced test of standard receptive, American English vocabulary, applicable to a wide age range." McCallum (1981) also added that no special training or equipment is needed to administer or score the test.

\section{Clinical Evaluation of Language Fundamentals Third Edition}

The Clinical Evaluation of Language Fundamentals Third Edition (CELF-3) was developed by Semel, Wigg, and Secord in 1996. The purpose of this instrument is to "measure a student's classroom communication and language learning difficulties." This is an individually administered rating scale given to parents and teachers that yields four scores: Listening (9 questions), Speaking (19 questions), Reading (6 questions), and Writing (6 questions). Normative data was collected from 1,208 parents, teachers, and students. Additional norming information was gathered from 117 language-disordered children.

Because this scale is observational, reliability between raters --parents and teachers-was found to be relatively low (.20 range for normal children and .30 for language disordered children). The correlations between raters on the specific subscales Listening and Speaking were somewhat higher, ranging from .40 to .49 . Within group reliability was much higher, ranging from .71 to .95 .

Content validity was established through interviews with language-disordered children, their teachers, and their parents, resulting in a pool of the most frequently occurring items. 
Criterion-related validity was established by comparing the receptive, expressive, and total language scores on the CELF-3 with the observational rating scales. Correlational coefficients ranged from .00 to -.46 . Construct validity was established by comparing the student, teacher, and parent ratings of students with and without language disorders. Significantly different ratings were obtained.

Hurford (1996) described the CELF-3 as a "very useful instrument to assist in the identification of language and communication difficulties and to assist in the planning of interventions." Haccoun (1996) added that the CELF-3_"taps the key elements of language skills with children," and it is a useful instrument to "zero in on specific language difficulties to better target possible interventions."

\section{Burks’ Behavior Rating Scale}

The Burks'Behavior Rating Scale was developed in 1968 by Harold Burks. This instrument was revised in 1997. He designed the instrument to "identify particular behavior problems and patterns of problems shown by children." He intended that it be used specifically with children in pre-school and kindergarten. The BBRS is an individually administered rating scale for parents and teachers comprised of 105 questions on a five-point scale, ranging from 1 "You have not noticed this behavior at all" to 5 "You have noticed this behavior to a very large degree". Normative data was collected from 464 preschool children ( 254 boys and 210 girls) in California, representing Anglo and Mexican-American cultures.

Item reliability averaged .705 based on a sample of 95 disturbed children. Test-retest reliability correlational coefficients ranged from .74 to .96 . No other information regarding reliability was provided in the manual.

Content validity was established through a review of the scale by 22 school psychologists in Los Angeles County who used the BBRS in their practice. Content validity was also assessed through reviews by 26 kindergarten teachers. Further validity studies have been conducted on the BBRS, establishing discriminant validity, construct, and factorial validity. 
Zlomke and Bush (1997) stated that the BBRS "is helpful in quantifying the severity of referred children's perceived deviance as observed by authority figures in their environment" and is based on "sound statistical development of the individual items and categories."

\section{Selection of Subjects}

Human Subjects approval was obtained from the University of North Texas Internal Review Board prior to the recruitment of subjects for this study. The population studied was comprised of pre-kindergarten and kindergarten children, ages 4-6, who qualified for speech therapy services at a public primary school in a rural area of northern Texas. According to the principal of the selected school, 45 children qualified for these services during the 2000-2001 school year, and this number was predicted to be the same or higher for the 2001-2002 school year.

The selected school had a population that was largely Anglo-American and MexicanAmerican. English was spoken by all children in the targeted population. Twenty-one children were selected from the targeted population based on returned parent consent forms and according to the following criteria: (1) the child qualified for speech therapy in the selected school district, (2) the child received speech therapy sessions during the course of the study, (3) the child was not currently in play therapy or any other form of psychotherapy, (4) the child was able to attend all 25 play therapy sessions at the scheduled times, and (5) the child's parents agreed to and signed a consent form (Appendix B) outlining the purposes and methods of the study.

The selected children were then randomly assigned to either the experimental group, which received 25 group play therapy sessions concurrently with their regularly scheduled speech therapy, or the comparison group, which received only their regularly scheduled speech therapy sessions. Sessions occurred during the months of November through May. 
The comparison group of 10 children consisted of 9 males and 1 female with an age range from 4 years, 11 months to 6 years, 6 months. Speech difficulties in the comparison group as diagnosed by the speech pathologist at the selected school consisted of:

1 case of severe articulation difficulty

1 case of severe expressive language delay

1 case of severe expressive language delay with moderate articulation difficulty

3 cases of moderate articulation difficulty

1 case of moderate articulation difficulty with stutter

1 case of moderate articulation difficulty with moderate expressive language delay

1 case of moderate expressive language delay with mild articulation difficulty

1 case of mild expressive language delay and mild articulation difficulty

Ethnicity of the comparison group consisted of 8 Caucasian and 2 Hispanic children. Six children lived with both parents, and 4 children came from single-parent households.

The experimental group of 11 children consisted of 9 males and 2 females with an age range from 3 years, 11 months to 6 years, 10 months. Speech difficulties in the experimental group as diagnosed by the speech pathologist at the selected school consisted of:

3 cases of severe articulation difficulty

2 cases of severe articulation difficulty with severe expressive language delay

1 case of severe expressive language delay

1 case of severe expressive language delay with moderate articulation difficulty

4 cases of moderate articulation difficulty

Ethnicity of the experimental group consisted of 9 Caucasian and 2 Hispanic children. Eight children lived with both parents, and 3 children came from single-parent households.

Collection of Data

Children who qualified for speech therapy services in the selected school district for the 2001-2002 school year were administered the Goldman Fristoe Test of Articulation, the Clinical 
Evaluation of Language Fundamentals Third Edition, and the Peabody Picture Vocabulary

Test-Revised prior to receiving services. These tests were administered by the speech pathologist at the selected school in September.

All parents of pre-kindergarten and kindergarten children who took these three tests and qualified for speech therapy received an introductory letter and consent form explaining the purpose and methods of the study (Appendix B). The letter was hand-delivered at school to the parents of the children. Those parents who were unable to receive the letter in person received it by mail. Twenty-one parents hand-returned the signed consent form directly to the investigator at the selected school. Parents were then hand-delivered the BBRS for rating their children, and these forms were completed at home, with the exception of one parent who could not read, in which case the consent form and the questions (both pre and post) were read to the parent by the investigator. All parents completed the BBRS and hand-returned it to the investigator at the selected school, with the exception of one parent whose child was in the experimental group.

Teachers were also asked to complete the BBRS for each identified child after they observed the child for a minimum of three weeks within the classroom environment. Teachers completed the BBRS at school and hand-returned it to the investigator at the school. One teacher did not complete the BBRS for two of the experimental participants, and one teacher did not complete questions $52-76$ of the BBRS for one of the comparison participants. Accounting for the observation period and the time needed to collect the forms from parents, all pre-testing was completed by November 7th. Play therapy sessions began after all pre-test information was collected.

Post-testing occurred in the second week of May. The GFTA, CELF-3, and the PPVT-R were administered by the speech pathologist and the investigator. The BBRS was completed by all parents and teachers. Post-testing was completed by the last week of May.

All information was kept confidential. Names or other identifiable information about parents and children will not be disclosed in any publication or discussion of this material. 
Information obtained from the instruments was recorded with a code number. Only the investigator had a list of the participant's names. All data and participants' names are kept in a secure location.

\section{Description of Treatment}

The investigator conducted child-centered group play therapy sessions with each dyad from the experimental group once a week for 30 minutes for a total of 25 sessions per dyad. All sessions were conducted in the play therapy room at the selected school. This room was located at the end of the hallway in a wing of the school and had a private entrance with a covered window on the door. The room was equipped with the following toys, which conformed to the Landreth (2002) recommendations:
(1) Sand
(11) Puppets
(21) Telephone
(2) Scoops/shovels/bucket
(12) Puppet theatre
(22) Riding car
(3) Plastic domestic animals
(13) Dramatic play clothes
(23) Pacifiers
(4) Plastic zoo animals
(14) Masks and hats
(24) Nursing bottles
(5) Plastic dinosaurs
(15) Baby dolls/clothes
(25) Dollhouse/family
(6) Toy gun/knife/sword
(16) Barbies/clothes
(26) Craft table/playdough
(7) Toy soldiers
(17) Play kitchen/food
(27) Cash register
(8) Toy car
(18) Crayons, paper
(28) Band aids
(9) Scotch tape
(19) Rope
(29) Medical kit
(10) Egg cartons
(20) Bop bag
(30) Drum/xylophone/mallet

After random selection to either the experimental or comparison group, children in the experimental group were randomly assigned to dyads according to age only. Children in each dyad were no more than one year apart in age.

The investigator was a licensed school counselor in the state of California with a Master's of Science degree in Educational Counseling. She was a kindergarten and first grade teacher for 12 years. She had completed 36 of her 66 hours of doctoral work at the 
commencement of this study. The investigator had completed courses in introduction to play therapy, group play therapy, and filial therapy at the University of North Texas and had completed over 100 clinical hours of doctoral practicum work with play therapy clients in both individual and group settings.

\section{Statistical Analysis}

Following the collection of the pre-test and post-test data, the GFTA, the CELF-3, and the PPVT-R were blind-scored by the speech pathologist at the selected school and by the investigator. The BBRS was blind-scored by the investigator and double-checked by a research assistant. Scores were then keyed into the computer by the researcher.

An analysis of covariance (ANCOVA) was computed to test the statistical and practical significance of the difference between the experimental group and the comparison group on the adjusted means for each of the eight hypotheses using SPSS for MS WINDOWS Release 6.12 (Norusis, 1955). In each case the post-test specified in each of the hypotheses was used as the dependent variable and the pre-test as the covariate. ANCOVA was used to adjust the group means on the post-test on the basis of the pre-test, thus statistically equating the control and experimental groups. Statistical significance of the differences between means was tested at the .05 level. On the basis of the ANCOVA, the hypotheses were either retained or rejected. 


\section{CHAPTER III}

\section{RESULTS AND DISCUSSION}

This chapter presents a description of the statistical and practical analyses performed, as well as the specific results of each hypothesis tested in the study. Also included is a discussion of the potential meaning of the obtained results, implications of the findings, and recommendations for future research.

\section{Results}

The results of this study are presented in the order the hypotheses were tested. Analyses of covariance were performed on hypotheses 1 through 12 . A level of significance of .05 was established as the criterion for either retaining or rejecting the hypotheses.

\section{Hypothesis 1}

The experimental group will attain a significantly higher mean total score on the Goldman Fristoe Test of Articulation (GFTA) post-test than will the comparison group.

Table 1 presents the pre and post-test means and standard deviations for the experimental and control groups. Table 2 presents the analysis of covariance data, showing the level of significance of the difference between the experimental and comparison groups' mean scores.

Table 1

Mean total scores on the Goldman Fristoe Test of Articulation (GFTA)

\begin{tabular}{lcccc}
\hline & \multicolumn{2}{c}{$\begin{array}{c}\text { Experimental Group } \\
(\mathrm{n}=11)\end{array}$} & \multicolumn{2}{c}{$\begin{array}{c}\text { Comparison Group } \\
(\mathrm{n}=10)\end{array}$} \\
& Pre-test & Post-test & Pre-test & Post-test \\
\hline Mean & & & & \\
SD & 75.45 & 88.27 & 79.70 & 89.00 \\
Total Cases $=21$ & 18.074 & 17.402 & 19.102 & 14.142 \\
\end{tabular}

Note: An increase in the mean score indicates an increase in overall articulation. 
Table 2

Analysis of covariance data for the Goldman Fristoe Test of Articulation (GFTA)

\begin{tabular}{lllllcc}
\hline $\begin{array}{l}\text { Source of } \\
\text { Variation }\end{array}$ & $\begin{array}{l}\text { Sum of } \\
\text { Squares }\end{array}$ & $\underline{\mathrm{d} f}$ & $\begin{array}{l}\text { Mean } \\
\text { Square }\end{array}$ & $\begin{array}{l}\underline{\mathrm{F}} \\
\text { Ratio }\end{array}$ & $\begin{array}{c}\text { Significance } \\
\text { of F }\end{array}$ & $\begin{array}{c}\text { Eta } \\
\text { Squared }\end{array}$ \\
\hline Main effects & 27.400 & 1 & 27.400 & .331 & .572 & .018 \\
Covariates & 3338.651 & 1 & 3338.651 & 40.345 & .000 & .692 \\
Error & 1489.531 & 18 & 82.752 & & & \\
Total Cases $=21$ & & & & & & \\
\end{tabular}

Table 2 shows the $\mathrm{F}$ ratio for the main effects was not significant at the <.05 level indicating that there was not a significant difference between the experimental and the comparison groups' overall growth in articulation skills as measured by the GFTA. On the basis of this data, hypothesis 1 was rejected. Table 2 also shows the Eta Squared for the main effects was .018, indicating a small practical significance as measured by the GFTA.

\section{Hypothesis 2}

The experimental group will attain a significantly higher mean total score on the Peabody Picture Vocabulary Test - Revised (PPVT-R) post-test than will the comparison group.

Table 3 presents the pre and post-test means and standard deviations for the experimental and comparison groups. Table 4 presents the analysis of covariance data, showing the level of significance of the difference between the experimental and comparison groups' mean scores. 
Table 3

Mean total scores on the Peabody Picture Vocabulary Test-Revised (PPVT-R)

\begin{tabular}{|c|c|c|c|c|}
\hline & \multicolumn{2}{|c|}{$\begin{array}{l}\text { Experimental Group } \\
\qquad(\mathrm{n}=11)\end{array}$} & \multicolumn{2}{|c|}{$\begin{array}{l}\text { Comparison Group } \\
(\mathrm{n}=10)\end{array}$} \\
\hline & Pre-test & Post-test & Pre-test & Post-tes \\
\hline Mean & 89.91 & 97.09 & 90.20 & 91.80 \\
\hline$S D$ & 13.225 & 11.104 & 16.792 & 15.383 \\
\hline Total & & & & \\
\hline
\end{tabular}

Note: An increase in the mean score indicates an increase in receptive language.

Table 4

Analysis of covariance data for the Peabody Picture Vocabulary Test-Revised (PPVT-R)

\begin{tabular}{|c|c|c|c|c|c|c|}
\hline $\begin{array}{l}\text { Source of } \\
\text { Variation }\end{array}$ & $\begin{array}{l}\text { Sum of } \\
\text { Squares }\end{array}$ & $\underline{\mathrm{d} f}$ & $\begin{array}{l}\text { Mean } \\
\text { Square }\end{array}$ & $\frac{\mathrm{F}}{\text { Ratio }}$ & $\begin{array}{c}\text { Significance } \\
\text { of } F\end{array}$ & $\begin{array}{c}\text { Eta } \\
\text { Squared }\end{array}$ \\
\hline Main effects & 157.419 & 1 & 157.419 & 1.881 & .187 & .095 \\
\hline Covariates & 1855.862 & 1 & 1855.862 & 22.172 & .000 & .552 \\
\hline Error & 1506.647 & 18 & 83.703 & & & \\
\hline \multicolumn{7}{|c|}{ Total Cases $=21$} \\
\hline
\end{tabular}

Table 4 shows the $\mathrm{F}$ ratio for the main effects was not significant at the $<.05$ level indicating that there was not a significant difference between the experimental and the comparison groups' overall growth in receptive language skills as measured by the PPVT-R. On the basis of this data, hypothesis 2 was rejected. Table 4 also shows the Eta Squared for the main effects was .095 indicating a medium practical significance as measured by the PPVT-R. Hypothesis 3 
The experimental group will attain a significantly higher mean score on the Receptive Language sub-test of the Clinical Evaluation of Language Fundamentals Third Edition (CELF3) post-test than will the comparison group.

Table 5 presents the pre and post-test means and standard deviations for the experimental and comparison groups. Table 6 presents the analysis of covariance data, showing the level of significance of the difference between the experimental and comparison groups' mean scores. Table 5

Mean total scores on the Receptive Language sub-test of the Clinical Evaluation of Language Fundamentals (CELF-3)

\begin{tabular}{lllll}
\hline & \multicolumn{2}{c}{$\begin{array}{c}\text { Experimental Group } \\
(\mathrm{n}=11) \\
\text { Pre-test }\end{array}$} & Post-test & \multicolumn{2}{c}{$\begin{array}{c}\text { Comparison Group } \\
(\mathrm{n}=10) \\
\text { Pre-test }\end{array}$} & Post-test \\
\hline Mean & & & & \\
SD & 90.82 & 94.27 & 89.40 & 92.60 \\
Total Cases $=21$ & 14.518 & 15.454 & 21.120 & 17.927 \\
\hline
\end{tabular}

Note: An increase in the mean score indicates an increase in receptive language.

Table 6

Analysis of covariance data for the Receptive Language sub-test of the Clinical Evaluation of Language Fundamentals Third Edition (CELF-3)

\begin{tabular}{|c|c|c|c|c|c|c|}
\hline $\begin{array}{l}\text { Source of } \\
\text { Variation }\end{array}$ & $\begin{array}{l}\text { Sum of } \\
\text { Squares }\end{array}$ & $\underline{\mathrm{d} f}$ & $\begin{array}{l}\text { Mean } \\
\text { Square }\end{array}$ & $\underline{F}_{\text {Ratio }}$ & $\begin{array}{c}\text { Significance } \\
\text { of } F\end{array}$ & $\begin{array}{c}\text { Eta } \\
\text { Squared }\end{array}$ \\
\hline Main effects & 3.740 & 1 & 3.740 & .021 & .886 & .001 \\
\hline Covariates & 2081.977 & 1 & 2081.977 & 11.716 & .003 & .394 \\
\hline Error & 3198.605 & 18 & 177.700 & & & \\
\hline \multicolumn{7}{|c|}{ Total Cases = 21} \\
\hline
\end{tabular}


Table 6 shows the $\mathrm{F}$ ratio for the main effects was not significant at the $<.05$ level indicating that there was not a significant difference between the experimental and the comparison groups' overall growth in receptive language skills as measured by the CELF-3. On the basis of this data, hypothesis 3 was rejected. Table 6 also shows the Eta Squared for the main effects was .001 indicating a small practical significance as measured by the CELF-3.

\section{Hypothesis 4}

The experimental group will attain a significantly higher mean score on the Expressive Language sub-test of the Clinical Evaluation of Language Fundamentals Third Edition (CELF3) post-test than will the comparison group.

Table 7 presents the pre and post-test means and standard deviations for the experimental and comparison groups. Table 8 presents the analysis of covariance data, showing the level of significance of the difference between the experimental and comparison groups' mean scores. Table 7

Mean total scores on the Expressive Language sub-test of the Clinical Evaluation of Language Fundamentals Third Edition (CELF-3)

\begin{tabular}{|c|c|c|c|c|}
\hline & \multicolumn{2}{|c|}{$\begin{array}{l}\text { Experimental Group } \\
\qquad(\mathrm{n}=11)\end{array}$} & \multicolumn{2}{|c|}{$\begin{array}{l}\text { Comparison Group } \\
\qquad(\mathrm{n}=10)\end{array}$} \\
\hline & Pre-test & Post-test & Pre-test & Post-test \\
\hline Mean & 89.36 & 96.55 & 92.70 & 89.50 \\
\hline$S D$ & 16.931 & 21.792 & 19.282 & 19.392 \\
\hline Total & & & & \\
\hline
\end{tabular}

Note: An increase in the mean score indicates an increase in expressive language. 
Table 8

Analysis of covariance data for the Expressive Language sub-test of the Clinical Evaluation of Language Fundamentals Third Edition (CELF-3)

\begin{tabular}{llccccc}
$\begin{array}{l}\text { Source of } \\
\text { Variation }\end{array}$ & $\begin{array}{l}\text { Sum of } \\
\text { Squares }\end{array}$ & $\underline{\mathrm{d} f}$ & $\begin{array}{l}\text { Mean } \\
\text { Square }\end{array}$ & $\begin{array}{l}\underline{\mathrm{F}} \\
\text { Ratio }\end{array}$ & $\begin{array}{c}\text { Significance } \\
\text { of F }\end{array}$ & $\begin{array}{c}\text { Eta } \\
\text { Squared }\end{array}$ \\
\hline Main effects & 498.120 & 1 & 498.120 & 2.295 & .147 & .113 \\
Covariates & 4226.643 & 1 & 4226.643 & 19.475 & .000 & .519 \\
Error & 3906.584 & 18 & 217.032 & & & \\
Total Cases $=21$ & & & & & & \\
\hline
\end{tabular}

Table 8 shows the $\mathrm{F}$ ratio for the main effects was not significant at the $<.05$ level indicating that there was not a significant difference between the experimental and the comparison groups' overall growth in expressive language skills as measured by the CELF-3.

On the basis of this data, hypothesis 4 was rejected. Table 8 also shows the Eta Squared for the main effects was .113 indicating a large practical significance as measured by the CELF-3.

\section{Hypothesis 5}

The experimental group will attain a significantly lower mean score on the Anxiety subtest of the Burks' Behavior Rating Scale (BBRS) post-test as rated by teachers than will the comparison group.

Table 9 presents the pre and post-test means and standard deviations for the experimental and comparison groups on the Anxiety sub-test of the BBRS as completed by the participants' teachers. Table 10 presents the analysis of covariance data, showing the level of significance of the difference between the experimental and comparison groups' mean scores. 
Table 9

Mean total scores on the Anxiety sub-test of the Burks' Behavior Rating Scale as completed by participants' teachers

\begin{tabular}{lllll}
\hline & \multicolumn{2}{c}{$\begin{array}{c}\text { Experimental Group } \\
(\mathrm{n}=9)\end{array}$} & \multicolumn{2}{c}{$\begin{array}{c}\text { Comparison Group } \\
(\mathrm{n}=10)\end{array}$} \\
& Pre-test & Post-test & Pre-test & Post-test \\
\hline & & & & \\
Mean & 8.78 & 8.36 & 6.50 & 6.40 \\
$S D$ & 4.438 & 4.342 & 1.900 & 2.066 \\
Total Cases $=19$ & & & & \\
\hline
\end{tabular}

Note: A decrease in the mean score indicates a decrease in symptoms of anxiety. Mean scores above 10 indicate significant symptoms of anxiety as measured by the BBRS.

Table 10

Analysis of covariance data for the Anxiety sub-test of the Burks'Behavior Rating Scale as completed by participant's teachers

\begin{tabular}{|c|c|c|c|c|c|c|}
\hline $\begin{array}{l}\text { Source of } \\
\text { Variation }\end{array}$ & $\begin{array}{l}\text { Sum of } \\
\text { Squares }\end{array}$ & $\underline{\mathrm{d} f}$ & $\begin{array}{l}\text { Mean } \\
\text { Square }\end{array}$ & $\underline{\text { Ratio }}$ & $\begin{array}{c}\text { Significance } \\
\text { of } F\end{array}$ & $\begin{array}{l}\text { Eta } \\
\text { Squared }\end{array}$ \\
\hline Main effects & 3.028 & 1 & 3.028 & .429 & .522 & .026 \\
\hline Covariates & 98.435 & 1 & 98.435 & 13.956 & .002 & .466 \\
\hline Error & 112.854 & 16 & 7.053 & & & \\
\hline \multicolumn{7}{|c|}{ Total Cases $=21$} \\
\hline
\end{tabular}

Table 10 shows the $\mathrm{F}$ ratio for the main effects was not significant at the $<.05$ level indicating that there was not a significant difference between the experimental and the comparison groups' symptoms of anxiety as measured by the BBRS. On the basis of this data, hypothesis 5 was rejected. Table 10 also shows the Eta Squared for the main effects was .026 indicating a small practical significance as measured by the BBRS. 


\section{Hypothesis 6}

The experimental group will attain a significantly lower mean score on the Anxiety subtest of the Burks' Behavior Rating Scale (BBRS) post-test as rated by parents than will the comparison group.

Table 11 presents the pre and post-test means and standard deviations for the experimental and comparison groups on the Anxiety sub-test of the BBRS as completed by the participants' parents. Table 12 presents the analysis of covariance data, showing the level of significance of the difference between the experimental and comparison groups' mean scores. Table 11

Mean total scores on the Anxiety sub-test of the Burks' Behavior Rating Scale as completed by participants' parents

Experimental Group
$(\mathrm{n}=10)$$\quad \begin{gathered}\text { Comparison Group } \\ (\mathrm{n}=10)\end{gathered}$

Pre-test Post-test Pre-test Post-test

$\begin{array}{lllll}\text { Mean } & 8.50 & 7.55 & 8.00 & 7.30 \\ S D & 3.274 & 2.382 & 3.127 & 1.947\end{array}$

Total Cases $=20$

Note: A decrease in the mean score indicates a decrease in symptoms of anxiety. Mean scores above 10 indicate significant symptoms of anxiety as measured by the BBRS. 
Table 12

Analysis of covariance data for the Anxiety sub-test of the Burks' Behavior Rating Scale as completed by participant's parents

\begin{tabular}{|c|c|c|c|c|c|c|}
\hline $\begin{array}{l}\text { Source of } \\
\text { Variation }\end{array}$ & $\begin{array}{l}\text { Sum of } \\
\text { Squares }\end{array}$ & $\underline{\mathrm{d} f}$ & $\begin{array}{l}\text { Mean } \\
\text { Square }\end{array}$ & $\frac{F}{\text { Ratio }}$ & $\begin{array}{c}\text { Significance } \\
\text { of } F\end{array}$ & $\begin{array}{l}\text { Eta } \\
\text { Squared }\end{array}$ \\
\hline Main effects & .190 & 1 & .190 & .056 & .815 & .001 \\
\hline Covariates & 30.896 & 1 & 30.896 & 9.166 & .008 & .350 \\
\hline Error & 57.304 & 17 & 3.371 & & & \\
\hline \multicolumn{7}{|c|}{ Total Cases $=21$} \\
\hline
\end{tabular}

Table 12 shows the $\mathrm{F}$ ratio for the main effects was not significant at the $<.05$ level indicating that there was not a significant difference between the experimental and the comparison groups' symptoms of anxiety as measured by the BBRS. On the basis of this data, hypothesis 6 was rejected. Table 12 also shows the Eta Squared for the main effects was .001 indicating a small practical significance as measured by the BBRS.

\section{Hypothesis 7}

The experimental group will attain a significantly lower mean score on the Sense of Identity sub-test of the Burks' Behavior Rating Scale (BBRS) post-test as rated by teachers than will the comparison group.

Table 13 presents the pre and post-test means and standard deviations for the experimental and comparison groups on the Sense of Identity sub-test of the BBRS as completed by the participants' teachers. Table 14 presents the analysis of covariance data, showing the level of significance of the difference between the experimental and comparison groups' mean scores. 
Table 13

Mean total scores on the Sense of Identity sub-test of the Burks' Behavior Rating Scale as completed by participants' teachers

\begin{tabular}{|c|c|c|c|c|}
\hline & \multicolumn{2}{|c|}{$\begin{array}{l}\text { Experimental Group } \\
\qquad(\mathrm{n}=9)\end{array}$} & \multicolumn{2}{|c|}{$\begin{array}{l}\text { Comparison Group } \\
\qquad(\mathrm{n}=9)\end{array}$} \\
\hline & Pre-test & Post-test & Pre-test & Post-test \\
\hline Mean & 8.22 & 8.27 & 6.00 & 6.40 \\
\hline$S D$ & 3.866 & 4.839 & 1.323 & 1.838 \\
\hline Total & & & & \\
\hline
\end{tabular}

Note: A decrease in the mean score indicates an increase in a positive sense of identity. Mean scores above 10 indicate significant symptoms of a poor sense of identity as measured by the BBRS.

Table 14

Analysis of covariance data for the Sense of Identity sub-test of the Burks' Behavior Rating Scale as completed by participant's teachers

\begin{tabular}{|c|c|c|c|c|c|c|}
\hline $\begin{array}{l}\text { Source of } \\
\text { Variation }\end{array}$ & $\begin{array}{l}\text { Sum of } \\
\text { Squares }\end{array}$ & $\underline{\mathrm{d} f}$ & $\begin{array}{l}\text { Mean } \\
\text { Square }\end{array}$ & $\frac{\mathrm{F}}{\text { Ratio }}$ & $\begin{array}{c}\text { Significance } \\
\text { of F }\end{array}$ & $\begin{array}{c}\text { Eta } \\
\text { Squared }\end{array}$ \\
\hline Main effects & .561 & 1 & .561 & .069 & .796 & .005 \\
\hline Covariates & 115.128 & 1 & 115.128 & 14.261 & .002 & .487 \\
\hline Error & 121.094 & 15 & 8.073 & & & \\
\hline Total Cases & & & & & & \\
\hline
\end{tabular}

Table 14 shows the $\mathrm{F}$ ratio for the main effects was not significant at the $<.05$ level indicating that there was not a significant difference between the experimental and the comparison groups' positive sense of identity as measured by the BBRS. On the basis of this data, hypothesis 7 was rejected. Table 14 also shows the Eta Squared for the main effects was .005 indicating a small practical significance as measured by the BBRS. 


\section{Hypothesis 8}

The experimental group will attain a significantly lower mean score on the Sense of Identity sub-test of the Burks'Behavior Rating Scale (BBRS) post-test as rated by parents than will the comparison group.

Table 15 presents the pre and post-test means and standard deviations for the experimental and comparison groups on the Sense of Identity sub-test of the BBRS as completed by the participants' parents. Table 16 presents the analysis of covariance data, showing the level of significance of the difference between the experimental and comparison groups' mean scores. Table 15

Mean total scores on the Sense of Identity sub-test of the Burks' Behavior Rating Scale as completed by participants' parents

\begin{tabular}{|c|c|c|c|c|}
\hline & \multicolumn{2}{|c|}{$\begin{array}{l}\text { Experimental Group } \\
\qquad(n=9)\end{array}$} & \multicolumn{2}{|c|}{$\begin{array}{l}\text { Comparison Group } \\
\qquad(\mathrm{n}=9)\end{array}$} \\
\hline & Pre-test & Post-test & Pre-test & Post-test \\
\hline Mean & 6.80 & 6.45 & 6.70 & 6.60 \\
\hline$S D$ & 3.048 & 2.018 & 33.368 & 3.134 \\
\hline \multicolumn{5}{|c|}{ Total Cases $=18$} \\
\hline
\end{tabular}

Note: A decrease in the mean score indicates an increase in a positive sense of identity. Mean scores above 10 indicate significant symptoms of a poor sense of identity as measured by the BBRS. 
Table 16

Analysis of covariance data for the Sense of Identity sub-test of the Burks' Behavior Rating Scale as completed by participant's parents

\begin{tabular}{|c|c|c|c|c|c|c|}
\hline $\begin{array}{l}\text { Source of } \\
\text { Variation }\end{array}$ & $\begin{array}{l}\text { Sum of } \\
\text { Squares }\end{array}$ & $\underline{\mathrm{d} f}$ & $\begin{array}{l}\text { Mean } \\
\text { Square }\end{array}$ & $\frac{\mathrm{F}}{\text { Ratio }}$ & $\begin{array}{c}\text { Significance } \\
\text { of F }\end{array}$ & $\begin{array}{c}\text { Eta } \\
\text { Squared }\end{array}$ \\
\hline Main effects & 1.754 & 1 & 1.754 & .005 & .945 & .028 \\
\hline Covariates & 65.159 & 1 & 65.159 & 17.970 & .005 & .945 \\
\hline Error & 61.641 & 17 & 3.626 & & & \\
\hline \multicolumn{7}{|c|}{ Total Cases $=18$} \\
\hline
\end{tabular}

Table 16 shows the $\mathrm{F}$ ratio for the main effects was not significant at the $<.05$ level indicating that there was not a significant difference between the experimental and the comparison groups' positive sense of identity as measured by the BBRS. On the basis of this data, hypothesis 8 was rejected. Table 14 also shows the Eta Squared for the main effects was .028 indicating a small practical significance as measured by the BBRS.

\section{Hypothesis 9}

The experimental group will attain a significantly lower mean score on the Withdrawal sub-test of the Burks'Behavior Rating Scale (BBRS) post-test as rated by teachers than will the comparison group.

Table 17 presents the pre and post-test means and standard deviations for the experimental and comparison groups on the Withdrawal sub-test of the BBRS as completed by the participants' teachers. Table 18 presents the analysis of covariance data, showing the level of significance of the difference between the experimental and comparison groups' mean scores. 
Table 17

Mean total scores on the Withdrawal sub-test of the Burks' Behavior Rating Scale as completed by participants' teachers

\begin{tabular}{|c|c|c|c|c|}
\hline & \multicolumn{2}{|c|}{$\begin{array}{l}\text { Experimental Group } \\
\qquad(\mathrm{n}=9)\end{array}$} & \multicolumn{2}{|c|}{$\begin{array}{l}\text { Comparison Group } \\
(\mathrm{n}=10)\end{array}$} \\
\hline & Pre-test & Post-test & Pre-test & Post-test \\
\hline Mean & 10.00 & 10.09 & 11.90 & 12.10 \\
\hline$S D$ & 3.354 & 5.147 & 5.763 & 5.763 \\
\hline \multicolumn{5}{|c|}{ Total Cases $=19$} \\
\hline
\end{tabular}

Note: A decrease in the mean score indicates a decrease in withdrawal behaviors. Mean scores above 12 indicate significant withdrawal behaviors as measured by the BBRS.

Table 18

Analysis of covariance data for the Withdrawal sub-test of the Burks'Behavior Rating Scale as completed by participant's teachers

\begin{tabular}{lrrrrrr}
$\begin{array}{l}\text { Source of } \\
\text { Variation }\end{array}$ & $\begin{array}{l}\text { Sum of } \\
\text { Squares }\end{array}$ & $\underline{\mathrm{d} f}$ & $\begin{array}{l}\text { Mean } \\
\text { Square }\end{array}$ & $\begin{array}{l}\underline{\mathrm{F}} \\
\text { Ratio }\end{array}$ & $\begin{array}{c}\text { Significance } \\
\text { of F }\end{array}$ & $\begin{array}{c}\text { Eta } \\
\text { Squared }\end{array}$ \\
\hline Main effects & .292 & 1 & .292 & .014 & .906 & .001 \\
Covariates & 197.440 & 1 & 197.440 & 9.706 & .007 & .378 \\
Error & 325.460 & 16 & 20.341 & & & \\
Total Cases & 19 & & & & & \\
\end{tabular}

Table 18 shows the $\mathrm{F}$ ratio for the main effects was not significant at the $<.05$ level indicating that there was not a significant difference between the experimental and the comparison groups' withdrawal behaviors as measured by the BBRS. On the basis of this data, hypothesis 9 was rejected. Table 18 also shows the Eta Squared for the main effects was .001 indicating a small practical significance as measured by the BBRS. 


\section{Hypothesis 10}

The experimental group will attain a significantly lower mean score on the Withdrawal sub-test of the Burks' Behavior Rating Scale (BBRS) post-test as rated by parents than will the comparison group.

Table 19 presents the pre and post-test means and standard deviations for the experimental and comparison groups on the Withdrawal sub-test of the BBRS as completed by the participants' parents. Table 20 presents the analysis of covariance data, showing the level of significance of the difference between the experimental and comparison groups' mean scores.

Table 19

Mean total scores on the Withdrawal sub-test of the Burks' Behavior Rating Scale as completed by participants' parents

Experimental Group
$(\mathrm{n}=10)$$\quad \begin{gathered}\text { Comparison Group } \\ (\mathrm{n}=10)\end{gathered}$

Pre-test Post-test Pre-test Post-test

$\begin{array}{lrrrr}\text { Mean } & 10.90 & 9.00 & 11.40 & 9.40 \\ S D & 4.122 & 3.130 & 5.562 & 3.204\end{array}$

Total Cases $=20$

Note: A decrease in the mean score indicates a decrease in withdrawal behaviors. Mean scores above 12 indicate significant withdrawal behaviors as measured by the BBRS. 
Table 20

Analysis of covariance data for the Withdrawal sub-test of the Burks' Behavior Rating Scale as completed by participant's parents

\begin{tabular}{|c|c|c|c|c|c|c|}
\hline $\begin{array}{l}\text { Source of } \\
\text { Variation }\end{array}$ & $\begin{array}{l}\text { Sum of } \\
\text { Squares }\end{array}$ & $\underline{\mathrm{d} f}$ & $\begin{array}{l}\text { Mean } \\
\text { Square }\end{array}$ & $\frac{\mathrm{F}}{\text { Ratio }}$ & $\begin{array}{c}\text { Significance } \\
\text { of } F\end{array}$ & $\begin{array}{l}\text { Eta } \\
\text { Squared }\end{array}$ \\
\hline Main effects & 1.627 & 1 & 1.627 & .003 & .956 & .018 \\
\hline Covariates & 101.763 & 1 & 101.763 & 19.763 & .000 & .537 \\
\hline Error & 87.537 & 17 & 5.149 & & & \\
\hline \multicolumn{7}{|c|}{ Total Cases $=20$} \\
\hline
\end{tabular}

Table 20 shows the $\mathrm{F}$ ratio for the main effects was not significant at the $<.05$ level indicating that there was not a significant difference between the experimental and the comparison groups' withdrawal behaviors as measured by the BBRS. On the basis of this data, hypothesis 10 was rejected. Table 20 also shows the Eta Squared for the main effects was .018 indicating a small practical significance as measured by the BBRS.

\section{Hypothesis 11}

The experimental group will attain a significantly lower mean score on the Social Conformity sub-test of the Burks' Behavior Rating Scale (BBRS) post-test as rated by teachers than will the comparison group.

Table 21 presents the pre and post-test means and standard deviations for the experimental and comparison groups on the Social Conformity sub-test of the BBRS as completed by the participants' teachers. Table 22 presents the analysis of covariance data, showing the level of significance of the difference between the experimental and comparison groups' mean scores. 
Table 21

Mean total scores on the Social Conformity sub-test of the Burks' Behavior Rating Scale as completed by participants' teachers

\begin{tabular}{lcccc}
\hline & \multicolumn{2}{c}{$\begin{array}{c}\text { Experimental Group } \\
(\mathrm{n}=9) \\
\end{array}$} & $\begin{array}{c}\text { Comparison Group } \\
(\mathrm{n}=10)\end{array}$ & \multicolumn{2}{c}{$\begin{array}{c}\text { Pre-test } \\
\text { Pre-test }\end{array}$} & Post-test & Post-test \\
\hline Mean & 13.00 & 13.36 & 10.30 & 11.40 \\
$S D$ & 6.538 & 6.801 & 1.889 & 3.534 \\
Total Cases $=19$ & & & & \\
\hline
\end{tabular}

Note: A decrease in the mean score indicates an increase in appropriate social interactions. Mean scores above 16 indicate a significant lack of appropriate social behaviors as measured by the BBRS.

Table 22

Analysis of covariance data for the Social Conformity sub-test of the Burks'Behavior Rating Scale as completed by participant's teachers

\begin{tabular}{|c|c|c|c|c|c|c|}
\hline $\begin{array}{l}\text { Source of } \\
\text { Variation }\end{array}$ & $\begin{array}{l}\text { Sum of } \\
\text { Squares }\end{array}$ & $\underline{\mathrm{d} f}$ & $\begin{array}{l}\text { Mean } \\
\text { Square }\end{array}$ & $\frac{F}{\text { Ratio }}$ & $\begin{array}{c}\text { Significance } \\
\text { of } F\end{array}$ & $\begin{array}{l}\text { Eta } \\
\text { Squared }\end{array}$ \\
\hline Main effects & 2.957 & 1 & 2.957 & .209 & .653 & .013 \\
\hline Covariates & 278.535 & 1 & 278.535 & 19.712 & .000 & .552 \\
\hline Error & 226.087 & 16 & 14.130 & & & \\
\hline \multicolumn{7}{|c|}{ Total Cases $=19$} \\
\hline
\end{tabular}

Table 22 shows the $\mathrm{F}$ ratio for the main effects was not significant at the <.05 level indicating that there was not a significant difference between the experimental and the comparison groups' appropriate social interactions as measured by the BBRS. On the basis of this data, hypothesis 11 was rejected. Table 22 also shows the Eta Squared for the main effects was .013 indicating a small practical significance as measured by the BBRS. 


\section{Hypothesis 12}

The experimental group will attain a significantly lower mean score on the Social Conformity sub-test of the Burks'Behavior Rating Scale (BBRS) post-test as rated by parents than will the comparison group.

Table 23 presents the pre and post-test means and standard deviations for the experimental and comparison groups on the Social Conformity sub-test of the BBRS as completed by the participants' parents. Table 24 presents the analysis of covariance data, showing the level of significance of the difference between the experimental and comparison groups' mean scores.

Table 23

Mean total scores on the Social Conformity sub-test of the Burks'Behavior Rating Scale as completed by participants' parents

\begin{tabular}{llll}
$\begin{array}{c}\text { Experimental Group } \\
(\mathrm{n}=10)\end{array}$ & \multicolumn{2}{c}{$\begin{array}{c}\text { Comparison Group } \\
(\mathrm{n}=10)\end{array}$} \\
Pre-test & Post-test & Pre-test & Post-test
\end{tabular}

$\begin{array}{lrrrr}\text { Mean } & 13.30 & 12.18 & 11.90 & 10.50 \\ S D & 4.398 & 5.759 & 5.425 & 5.169\end{array}$

Total Cases $=20$

Note: A decrease in the mean score indicates an increase in appropriate social interactions. Mean scores above 16 indicate a significant lack of appropriate social interactions as measured by the BBRS. 
Table 24

Analysis of covariance data for the Social Conformity sub-test of the Burks'Behavior Rating Scale as completed by participant's parents

\begin{tabular}{lrrrrrr}
$\begin{array}{l}\text { Source of } \\
\text { Variation }\end{array}$ & $\begin{array}{l}\text { Sum of } \\
\text { Squares }\end{array}$ & $\underline{\mathrm{d} f}$ & $\begin{array}{l}\text { Mean } \\
\text { Square }\end{array}$ & $\begin{array}{l}\underline{\mathrm{F}} \\
\text { Ratio }\end{array}$ & $\begin{array}{c}\text { Significance } \\
\text { of F }\end{array}$ & $\begin{array}{l}\text { Eta } \\
\text { Squared }\end{array}$ \\
\hline Main effects & .378 & 1 & .378 & .054 & .819 & .003 \\
Covariates & 452.908 & 1 & 452.908 & 64.597 & .000 & .791 \\
Error & 119.192 & 17 & 7.011 & & & \\
Total Cases $=$ & & & & & & \\
\end{tabular}

Table 24 shows the $\mathrm{F}$ ratio for the main effects was not significant at the $<.05$ level indicating that there was not a significant difference between the experimental and the comparison groups' appropriate social interactions as measured by the BBRS. On the basis of this data, hypothesis 12 was rejected. Table 24 also shows the Eta Squared for the main effects was .003 indicating a small practical significance as measured by the BBRS.

\section{Discussion}

The results from this study, along with therapeutic observations and teachers' and parents' comments provide information regarding the effectiveness of child-centered group play therapy for children with speech difficulties. Although not statistically significant at the .05 level, statistical results suggest improvement in speech factors and emotional factors for those children who received group play therapy as compared to those who received only speech therapy. In particular, child-centered group play therapy was found to have a large practical significance in improving children's expressive language. Child-centered group play therapy was also found to have a medium practical significance in improving children's receptive language. Of the 12 hypotheses in this study, none were retained based on statistical results. In 
eleven of the twelve hypotheses, positive movement in the expected direction did occur. An interpretation of the results for each hypothesis is presented below.

\section{Hypothesis 1: Improved Articulation}

As shown in Table 1, the experimental group obtained a 12.82 increase in the mean score on the Goldman Fristoe Test of Articulation as compared to the comparison group, who obtained an increase of only 9.3 in the mean score. Although not statistically significant, these scores do indicate a slightly larger margin of increase for those children who received group play therapy than for those who did not.

One possible explanation for the non-significant results concerns the nature of the speech difficulty being tested. Hoff (2001) described delays in the development of phonological production in children in terms of anatomical and physiological characteristics. "Sound production is shaped by motor capacity, and the development of sound production is shaped by the development of motor capacity" (p.140). Thus, one could argue that a treatment which addresses psychological and emotional factors such as group play therapy would have little impact upon purely physiological symptoms. However, four existing studies in which children improved specific articulation errors through the medium of play (Bouillion, 1973; Dupont et al., 1953; Kupperman et al., 1980; Sokoloff, 1959) would appear to lessen the validity of this argument.

A second consideration is the composition of the experimental group and the comparison group with respect to the number of children in each group with articulation difficulties and the severity of the difficulty. In the experimental group, five children exhibited severe articulation difficulties, and five exhibited moderate articulation difficulties. In the comparison group, one child exhibited severe articulation difficulties, six exhibited moderate difficulties, and two exhibited mild difficulties as measured by the Goldman Fristoe Test of Articulation. One could conclude that because the children in the experimental group demonstrated more severe 
articulation difficulties, their somewhat larger gain in the mean score simply reflects the fact that these children had a wider numerical span in which to improve.

A closer look at where the pre-test mean scores (expressed in Standard Scores) lie on the normal distribution curve, however, reveals that both the experimental group and the comparison group fell within the Moderately Low range. In other words, the comparison group mean score for the pre-test (79.70) was only 4.25 points higher than the experimental group mean score for the pre-test (75.45) - both falling within the Moderately Low range on the normal distribution curve. Post test mean scores were virtually the same - the comparison group post-test mean score (89.00) was only .73 points higher than the experimental group post-test mean score (88.27), both falling within the Low Average range on the normal distribution curve. Given that the comparison group did not obtain pre-test scores in the Average, High Average, or Moderately High range, it would appear that the comparison group children as well had a wide numerical span in which to improve.

A third, and statistically more likely explanation for the non-significant results involves the size of the experimental and comparison groups. According to Heppner, Kivlighan, and Wampold (1999), a small sample size can impact the power of the statistical procedure and the overall results. "Even given a treatment that is effective, a study comparing the treatment group to a control group will not necessarily result in a statistically significant finding - it is entirely possible that even though an effect exists, the obtained test statistic is not sufficiently large to reach significance" (p. 327). The sample size in the present study consisted of only 11 children in the experimental group and 10 in the comparison group. For the analysis of covariance statistical procedure utilized, Gall, Borg, and Gall (1996) suggested a minimum sample size of 15 (p.189).

In light of the above explanation, a definite rejection of child-centered group play therapy for children with speech difficulties seems unwarranted. Children with articulation difficulties might be able to improve their phonetic production skills through group play therapy in 
conjunction with directive speech therapy more than with directive speech therapy alone. The accepting and non-directive elements of group play therapy may enable children to attempt and practice the phonetic sounds they hear modelled in the therapist's responses in an environment free from correction and required oral repetition.

\section{Hypotheses 2 and 3: Increased Receptive Language}

The results from the testing of this hypothesis yielded findings that showed childcentered group play therapy had a medium practical significance in improving the receptive language skills of children in the experimental group. As shown in Table 4, the Eta Squared value of .095 indicates the possibility that children in the experimental group may have improved their vocabulary through child-centered group play therapy in conjunction with directive speech therapy. Factors found within child-centered group play therapy may have provided the children with an environment in which the meaning of new words could be understood and internalized.

If greater increases in receptive language among children in the experimental group is substantiated by further research, an explanation may be found in the dynamics of the group play therapy experience. Landreth and Sweeney (1999) described a rationale for utilizing group play therapy with children: "The group provides opportunity for vicarious and direct learning" (p. 53), which would indicate that children in group play therapy can learn vocabulary words from each other. In addition to the therapist allowing the children to be responsible for generating their own meaning from their play experiences, the demonstrated increase in receptive language among the experimental group might also be supported by clinical observations made by the researcher of increased verbal interactions during each session (see Hypothesis 4: Increased Expressive Language).

Statistically, the experimental group demonstrated a 7.18 increase in the mean score on the Peabody Picture Vocabulay Test as compared to the comparison group, who demonstrated an increase of only 1.60 in the mean score. Although not statistically significant, these scores do 
indicate a larger margin of increase for those children who received group play therapy than for those who did not.

On the normal distribution curve, both the experimental and comparison group pre-test and post test mean scores fell within the Low Average range. This finding suggests that both groups had a wide enough numerical span on the PPVT-R to show improvement. However, the post test mean score for the experimental group (97.09) was 5.29 points higher than the comparison group post test mean score (91.80). This finding indicates that those children who received group play therapy in conjunction with directive speech therapy increased the number of words they could understand more than those children who received only directive speech therapy.

The meaning of the difference between means is brought further into question by the possibility that children in the experimental group had an advantage in taking the PPVT-R. The format of the PPVT-R involves a series of cards with four pictures on each card. The tester instructs the child to "point to the ___, , and the child responds non-verbally by pointing to the picture that the tester has indicated. It is important to note that some of the items on this test are actual items in the playroom (drum, feather, painting, calculator, tambourine). Exposure to these items may have biased the children who received group play therapy and made them more likely to identify these items than those children who did not receive play therapy and may not have come into contact with some of these items on a regular basis. It is conceivable that a child could have played with some of these items, not known the label for them (since play therapists do not label the toys for the children [Landreth, 2002, p. 222]), and asked a parent at home to provide the vocabulary word. Children in the comparison group would not have had this advantage. Though unlikely, this advantage remains a possibility.

On the other hand, the PPVT-R may not have fully detected improvements in the experimental group. The PPVT-R consists of only three feeling words (words that a play therapist uses most with children in the playroom). These vocabulary words (horrible, surprised, 
exhausted) do not appear in the test until the $78^{\text {th }}$ item, a point which most children in the study did not reach. In addition, the second instrument used to test receptive language skills, the CELF-3, contains only two references to feelings ("The boy is sleepy," and "The boy is crying because his airplane broke."). This lack of "playroom lexicon" on the measurement instruments may have contributed to the lack of statistically significant findings. It is possible that children in the experimental group greatly increased their feeling words vocabulary but the instruments failed to measure this change because of how they were designed.

As shown in Table 5, the experimental group demonstrated a 3.45 increase in the mean score on the receptive language subtest of the CELF-3 as compared to the comparison group, who demonstrated an increase of only 3.20 in the mean score. Although this margin of increase is not as wide as shown on the PPVT-R, it is consistent with the experimental group demonstrating a higher increase in the mean score than the comparison group.

On the normal distribution curve, both the experimental and comparison group pre-test and post test mean scores fell within the Low Average range. This finding suggests that both groups had a wide enough numerical span on the receptive language subtest of the CELF-3 to show improvement. The post test mean score for the experimental group (94.27) was 1.67 points higher than the comparison group post test mean score (92.60). This result further indicates that those children who received group play therapy in conjunction with directive speech therapy increased the number of words they could understand more than those children who received only directive speech therapy.

The statistically non-significant results for the second hypothesis might be explained in terms of small sample size, as described for the first hypothesis. With a larger sample size, the statistical power would be increased, thus increasing the probability of finding significance if it were present. The result of $\mathrm{p}<.187$ approaches significance, although it does not meet the required level of .05 . One might also argue that because the therapist uses the words of the child and does not provide labels for the toys, the playroom environment is not rich enough in new 
vocabulary (for things, not feelings) for the child to make significant increases in receptive language.

\section{Hypothesis 4: Increased Expressive Language}

Child-centered group play therapy was found to have a large practical significance for improving children's expressive language. Table 8 shows the Eta Squared calculation for the third hypothesis to be .113 , which reflects a large practical significance. Given this figure, and the possibility that a small sample size was responsible for the differences in means not reaching statistical significance, one can argue that speech therapy programs designed for children with expressive language delays might do well to add a non-directed free play component.

Speech therapists who receive training in how to make child-centered therapeutic responses would most likely facilitate the development of expressive language in the children they serve more so than if they utilized directive responses alone. The non-judgemental, nondirective, and accepting environment of the playroom seems to provide children with the freedom and confidence to express themselves without fear of rejection, over-correction, or uninteresting oral repetitions which are not connected to their immediate, subjective world. Indeed, two of the children who were receiving child-centered group play therapy sessions were exited from the speech program before the conclusion of the study. The researcher's clinical observations also support the notion that the child-centered group play therapy environment fostered an increase in verbal expression.

Case notes maintained by the researcher during the course of the study indicated an increase in overall verbal expression among children in the experimental group. After randomly selected group play therapy sessions, the researcher made a subjective rating on a 10-point scale of the amount of expressive language used by each child during a session (Appendix C). One represented a rating of verbally non-expressive for the majority of the session, and 10 represented a rating of full verbal expression for the majority of the session. These numbers are summarized in the following table: 
Table 25

Mean rating for amount of verbal expression during group play therapy sessions

\begin{tabular}{ll} 
& $\begin{array}{c}\text { Experimental Group } \\
(\mathrm{n}=11)\end{array}$ \\
Phase of Therapy & Rating \\
\hline Sessions 1-8 & 4.45 \\
Sessions $9-18$ & 6.09 \\
Sessions 18-25 & 8.00 \\
\hline
\end{tabular}

Table 25 shows positive movement towards increased expressive language usage during group play therapy sessions, thus lending further support for the notion that child-centered group play therapy increases expressive language skills, despite the statistical results from the analysis of covariance yielding $\mathrm{p}<.147$. The possibility of bias on the part of the researcher in rating the amount of verbal expression can not, however, be overlooked.

As shown in Table 7, the experimental group demonstrated a 7.19 increase in the mean score on the expressive language subtest of the CELF-3 as compared to the comparison group, who demonstrated a decrease (indicating the comparison group's expressive language skills actually got worse) of 3.2 in the mean score. Although this difference did not prove to be statistically significant after performing the analysis of covariance procedure, these scores do indicate a very large margin of increase in expressive language skills for those children who received group play therapy.

On the normal distribution curve, both the experimental and comparison group pre-test mean scores fell within the Low Average range. This result suggests that both groups had a wide enough numerical span on the expressive language subtest of the CELF-3 to show improvement. However, the post test mean score for the experimental group (96.55) was 7.05 points higher than the comparison group post test mean score (89.50). This finding places the 
experimental group post test scores within the Average range on the normal distribution curve, as opposed to the comparison group post test scores, which remained in the Low Average range, further indicating that those children who received group play therapy in conjunction with directive speech therapy may have increased their ability to verbally express themselves to a much greater extent than children who received only directive speech therapy.

Of noteworthy importance is the number of cases of expressive language delay present in each group prior to treatment. In the comparison group, two children had severe expressive language delays, two children had moderate expressive language delays, and 1 child had a mild expressive language delay. In the experimental group, four children had severe expressive language delays. Although the comparison group had a greater number of children with expressive language difficulties, the experimental group had more severe cases.

The statistically non-significant results for the third hypothesis might again be explained in terms of small sample size, as described for the first three hypotheses. With a larger sample size, the statistical power would be increased, thus increasing the probability of finding statistically significant differences between groups if it were present. The result of $p<.147$ approaches significance, although it does not meet the required level of .05 .

\section{Hypothesis 5 and 6: Decreased Anxiety}

As shown in Table 9, the experimental group demonstrated a .42 decrease in the mean score on the Anxiety subtest of the teacher-rated BBRS (indicating a decrease in symptoms of anxiety) as compared to the comparison group, who demonstrated a decrease of only .10 in the mean score. As shown in Table 11, the experimental group demonstrated a .95 decrease in the mean score on the Anxiety subtest of the parent-rated BBRS as compared to the comparison group, who demonstrated a decrease of only .70 in the mean score. Two highly probable explanations exist to account for the lack of significance found after computing the analysis of covariance for this hypothesis. 
The first reason lies in the fact that certain assumptions were made at the beginning of this study, namely, that the identified children with speech difficulties who participated in the study were currently experiencing anxiety due to their condition. Given that the mean pre-test scores on the Anxiety subtest of the teacher-rated and parent-rated BBRS for both the experimental and comparison groups fell within the non-significant range (indeed, both sets of pre-test scores were only 2 points greater than the lowest possible score), this suggests that both groups did not have a wide enough numerical span on this instrument to show improvement. Therefore, lack of significance is not surprising because nearly all the children in this study did not appear to be experiencing any significant symptoms of anxiety. Had the results from the BBRS pre-test been utilized by the researcher as a screening instrument only -- for this hypothesis as well as the remaining five hypotheses -- post-testing would not have been necessary due to the absence of any significant symptoms.

However, clinical observations confirmed that one experimental group child whose pretest score fell within the significant range for anxiety as rated by the child's teacher decreased to non-significance on the post-test. This child played out mostly themes of control in the playroom that involved handcuffs, taking people "to jail," and role-playing fireman, policemen, and other figures of authority. By the last session, this child allowed his play partner to handcuff him and take him away to jail, after which he rolled on top of his partner and hugged him. The evolution of his behaviour appeared to indicate movement toward resolution of themes involving power and control which, logically, seem related to anxiety.

A second explanation for the lack of statistical significance lies again in the small sample size obtained for this study. However, since the pre-test scores for anxiety were so low, a larger sample size may not have provided enough statistical power for the results to be significant.

\section{Hypothesis 7 and 8: Increased Self-Esteem}

As shown in Table 13, the experimental group demonstrated a .05 increase in the mean score on the Sense of Identity subtest of the teacher-rated BBRS (indicating an increase in 
symptoms of low self-esteem) as compared to the comparison group, who demonstrated a greater increase (.40) in the mean score (indicating a slightly greater increase in symptoms of low-self esteem). As shown in Table 15, the experimental group demonstrated a .35 decrease in the mean score on the Sense of Identity subtest of the parent-rated BBRS (indicating a decrease in symptoms of low self-esteem) as compared to the comparison group, who demonstrated a decrease of only .10 in the mean score.

To account for the lack of significance found after computing the analysis of covariance for this hypothesis, one must look at the two sets of pre-test scores (experimental and comparison) for both the teacher-ratings and the parent-ratings on this instrument. Both sets of pre-test mean scores were, on average, only 1.93 points greater than the lowest possible score (low scores indicating no symptoms of low self-esteem). Therefore, both groups did not have a wide enough numerical span on this instrument to show improvement. This finding suggests that the children in this study were not exhibiting any symptoms of low self-esteem as seen by either their parents or teachers. One can conclude that the results obtained for this hypothesis (as well as others connected to this instrument) were impacted by the fact that no evident symptoms were reported and by the violation of a basic statistical assumption that scores for parametric tests such as an analysis of covariance are normally distributed (Heppner, et al., 1999).

Only three children in the experimental group received a significant rating on the Sense of Identity pre-test; all three children received lower ratings on the post-test. One child moved from the significant range (score of 15) to the insignificant range (score of 9) as rated by the parent. Anecdotal notes kept by the researcher included a statement by this child's teacher: "(this child) has really come out of his shell. He has really blossomed."

Two children from the experimental group stayed in the significant range on the Sense of Identity subscale, but with lower scores (16 down to 14 and 19 down to 13 , both as rated by the teacher). Only one child in the comparison group received a significant rating on the Sense of Identity pre-test. This child was rated only one point lower on the postest (16 down to 15) as 
rated by the teacher, still placing the child on the high end of the significant range at the end of the study. Whereas these reported differences are minimal between the experimental and comparison groups in terms of increased self-esteem, the tendency of the experimental group to demonstrate a greater decrease in symptoms remains consistent. Lack of statistical significance may be attributable to the unequal distribution of scores.

\section{Hypothesis 9 and 10: Decreased Withdrawal}

As shown in Table 17, the experimental group demonstrated a .09 increase in the mean score on the Withdrawal subtest of the teacher-rated BBRS (indicating an increase in withdrawal behaviors) as compared to the comparison group, who demonstrated a greater increase (.20) in the mean score (indicating a slightly greater increase in withdrawal behaviors). As shown in Table 19, the experimental group demonstrated a 1.9 decrease in the mean score on the Withdrawal subtest of the parent-rated BBRS (indicating a decrease in withdrawal behaviors) as compared to the comparison group, who demonstrated a decrease of 2.0 in the mean score. It would appear that the results obtained from this subtest of the BBRS cancel each other out; according to the teachers, both groups of children slightly increased their withdrawal behaviors, and according to the parents, both groups of children slightly decreased their withdrawal behaviors. This disparity indicates the difficulties involved with utilizing subjective rating scales in a quantitative study designed to measure changes in observable behavior.

In order to further explain the lack of significance found after computing the analysis of covariance for this hypothesis, one can again look at the two sets of pre-test scores (experimental and comparison) for both the teacher-ratings and the parent-ratings on this instrument. Both sets of pre-test mean scores were, on average, only 4.59 points greater than the lowest possible score (low scores indicating no withdrawal behaviors). To exhibit significant withdrawal behaviors, a child must have scored 13 or greater on this subtest. Mean scores for both groups were all below this figure, with the closest one being the post test score for the comparison group as rated by the 
teachers (12.10). Therefore, both groups had an extremely small numerical span on this instrument to show improvement.

The numbers described above suggest that the children in this study were exhibiting no or very little withdrawal behaviors as observed by either their parents or teachers. This is a very curious result, given that numerous studies have demonstrated correlations between withdrawal behaviors and speech difficulties (Audet et al., 1990; Bishop, 1994; Bitler et al., 1993; Donahue et al., 1999; Hubbell, 1981; McGregor, 1993; Mogford-Bevan, 1994). Differences in the instruments used by researchers in these studies may account for the discrepancy. One can also speculate that "the primary problem with ratings of other persons and events is that the ratings may be systematically biased" (Heppner, et al., 1999, p. 309). It is arguable that parents rated their children lower on observed withdrawal behaviors because they did not wish their child to appear unsociable or isolated to the researcher, given that the setting in which the study was conducted was the child's first school experience. As well, the teachers may have been influenced by the "halo effect" (Gall et al., 1996, p. 340), in which they formed positive early impressions of the children in the study and these personal biases impacted their ratings for those individuals.

A closer look at the breakdown of scores reveals that six children in the experimental group received a significant rating on the Withdrawal pre-test, and all but one of the children received lower ratings on the post-test as rated by the parents. Three of the children moved from the significant range (scores of 14,15 , and 13 respectively) to the insignificant range (scores of 6,7 , and 7 respectively) on the post test, and three of the children stayed in the significant range, but with two children obtaining lower scores (18 down to 15, and 15 down to 13) and one child maintaining the same score on both the pre and post test (score of 9).

Five children in the comparison group received a significant rating on the Withdrawal pre-test; four of the children received lower ratings on the post-test as rated by the teachers. Two of the children moved from the significant range (scores of 19 and 18 respectively) to the 
insignificant range (scores of 12 and 9 respectively), one child stayed in the significant range (19 down to 15 ) and one child moved into the very significant range (18 up to 24.) Lack of statistical significance may again be attributed to the unequal distribution of scores.

\section{Hypothesis 11 and 12: Increased Positive Social Interaction}

This hypothesis is indirectly linked to the previous hypothesis. Generally speaking, if a child demonstrates a decrease in withdrawal behaviors, one can assume that the child is increasing social interactions with his or her peers. These interactions can take a positive or negative form. This hypothesis was designed to measure the positive social interactions exhibited by the children in the study as observed by their teachers and parents. It is important to note that the subtest of the BBRS utilized in this study measures the amount of negative social interactions displayed by the children as observed by parents and teachers.

Table 21 shows that the experimental group demonstrated a .36 increase in the mean score on the Social Conformity subtest of the teacher-rated BBRS (indicating an increase in negative interactions) as compared to the comparison group, who demonstrated a greater increase (1.1) in the mean score (indicating a slightly greater increase in negative interactions). As shown in Table 23, the experimental group demonstrated a 1.12 decrease in the mean score on the Social Conformity subtest of the parent-rated BBRS (indicating a decrease in negative interactions) as compared to the comparison group, who demonstrated a decrease of 1.4 in the mean score. Once again, it would appear that the results obtained from this subtest of the BBRS cancel each other out; acccording to the teachers, both groups of children slightly increased their negative interactions, and according to the parents, both groups of children slightly decreased their negative interactions. It is all the more reasonable to attribute some form of personal observer bias to the results of these subtests.

It must be noted, however, that all the mean scores for this subtest did fall within the significant range. Thus, the argument that the scores were not evenly distributed, as was the case in the aforementioned subtests of the BBRS, cannot be made. It is apparent that both groups did 
have a wide enough numerical span on this instrument to show improvement. The failure of the children in the experimental group to significantly reduce their negative interactions through the medium of group play therapy remains to be explained.

Case notes maintained by the researcher during the course of the study also point in the opposite direction, namely, that children displayed more positive connectedness with their partners as the course of therapy progressed. After randomly selected group play therapy sessions, the researcher made a subjective rating on a 10-point scale of the perceived connectedness or isolation of each child during a session (Appendix C). One represented a rating of isolation for the majority of the session, and 10 represented a rating of connectedness for the majority of the session. These numbers are summarized in the following table:

Table 26

Mean rating for amount of positive social connectedness during group play therapy sessions

Experimental Group $(\mathrm{n}=11)$

Phase of Therapy

Sessions $1-8$

Sessions 9-18

Sessions $18-25$
Rating

6.16

Table 26 shows slight movement towards positive social connectedness during group play therapy sessions, as observed by the therapist. During play sessions, the therapist looked for occurrences of play invitations by one play partner to the other, positive statements made by one play partner to the other, or inclusion of one play partner by the other in play behaviours that did not include attacks of anger or aggression towards the play partner. Again, the possibility of bias on the part of the researcher must be considered. However, given such a wide disparity between observations reported by teachers, parents, and the researcher, the notion that child-centered 
group play therapy increased positive social interactions among the children in the experimental group cannot be supported from the results obtained from the testing of this hypothesis.

\section{Summary}

Child-centered group play therapy was shown to have a large practical significance in increasing children's expressive language as measured by the CELF-3. The results of the analysis of covariance, while not statistically significant, did approach significance ( $\mathrm{p}<.147)$. Post test mean scores for the experimental group increased 7.19 points, while post test mean scores for the comparison group decreased 3.21 points, indicating an increase in expressive language skills for the experimental group and a decrease in expressive language skills for the comparison group. Small sample size may have contributed to the lack of statistical significance as calculated by the analysis of covariance.

Child-centered group play therapy was shown to have a medium practical significance in increasing children's receptive language as measured by the PPVT-R. The results of the analysis of covariance, while not significant, did yield a relatively low probability that results could be attributed to chance rather than to the experimental treatment of group play therapy. Post test mean scores for the experimental group increased 7.18 points, while post test mean scores for the comparison group increased only 1.60 points, indicating a greater increase in receptive language skills for the experimental group as compared to the comparison group. Small sample size may have contributed to the lack of statistical significance as calculated by the analysis of covariance.

Of the twelve hypothesis tested in this study, none were retained based on statistical significance at the .05 level. Small sample size, failure of the scores to meet the assumption of normal distribution for parametric tests, and rater bias may be contributing factors to the lack of significant findings. However, eleven of the twelve hypotheses addressing emotional factors and speech factors did show greater improvement for children who participated in child-centered group play therapy in addition to their regular directive speech therapy. 
Child-centered group play therapy was shown to have a small yet positive impact upon children's articulation skills. Post test mean scores for the experimental group increased 12.82 points, while post test mean scores for the comparison group increased only 9.3 points, indicating a greater increase in articulation for the experimental group as compared to the comparison group. Small sample size may have contributed to the lack of statistical significance as calculated by the analysis of covariance.

Child-centered group play therapy was also shown to have a small yet positive impact upon children's anxiety as measured by the BBRS. Post test mean scores for the experimental group decreased .42 points as rated by teachers and .95 points as rated by parents, while post test scores for the comparison group decreased by only .10 points as rated by teachers and .70 points as rated by parents. Although not significant at the .05 level, these results indicate a slightly larger decrease in symptoms of anxiety among those children who received group play therapy as compared to those who did not. Small sample size and lack of normal distribution may have contributed to the lack of statistical significance as calculated by the analysis of covariance.

Child-centered group play therapy was shown to have a mixed effect upon children's self-esteem, withdrawal behaviors, and positive social interactions as measured by the BBRS. Teachers observed slight increases in low self-esteem, withdrawal behaviors, and negative social interactions among children in the experimental group. While these increases were lower in the experimental group than in the comparison group, conclusions cannot be clearly drawn due to the fact that parents observed slight decreases in low self-esteem, withdrawal behaviors, and negative social interactions among children in the experimental group. These decreases were greater for the experimental group than the comparison group in the area of low self-esteem, yet greater for the comparison group than the experimental group in the areas of withdrawal behaviors and negative social interactions. Rater bias may have contributed to the lack of statistical significance as calculated by the analysis of covariance. 


\section{Limitations}

1. A threat to internal validity exists with regards to maturation. Because of the length of the study and the age of the participants, developmental changes in physical and emotional areas were likely to impact the outcome, irrespective of the treatment administered.

2. Because the speech pathologist' room was located near the room designated for group play therapy sessions, it is possible that the speech pathologist may have seen students walking to the playroom for their sessions, thus compromising the masking of scoring.

3. Teachers who completed the BBRS were also aware of which children left their room for play sessions, thus adding to the possibility of rater bias.

4. Outside occurrences in the lives of the participants (which might include but are not limited to: divorce of parents, death of a pet, or scholastic difficulties) could not be controlled by and were not assessed by the investigator. These possible occurrences may have impacted or altered the participants' emotional state during the course of the study.

5. Less than half of the available parents whose children met the criteria for the study returned the consent form.

6. Because the participants exhibited a wide range and level of speech difficulties, equating the comparison and experimental groups was difficult, because participants were randomly assigned to groups.

7. One pre-test in the experimental group was incomplete, and three of the post-test instruments were incomplete.

8. The researcher assisted the speech pathologist in administering the GFTA, which may have resulted in biased scoring because the researcher had a qualitatively different relationship with the children in the experimental group and may have 
trained her ear to understand the speech of the children in the experimental group in a different way than the speech pathologist.

9. Small sample size effected the power of the statistical procedures, thus compromising the probability of obtaining significance.

10. On three of the subtests of the BBRS, the assumption that scores for parametric tests are normally distributed was not met.

Based on the results of this study, the following recommendations and suggestions are offered:

\section{Recommendations for Further Research}

1. Conduct a replication of this study using a larger sample size with a minimum of 15 subjects per group. This will increase the power of the statistical measure and help to meet the assumption of normal distribution of scores.

2. Instead of randomly assigning children to the experimental or comparison group, utilize purposeful assignment in order to balance the type and severity of children's speech difficulties between the two groups. This will help control for inequality of groups on the variables measured.

3. In addition to subjective rating scales, utilize an assessment tool such as the Joseph Preschool and Primary Self Concept Screening Test or the Harter Pictorial Scale of Perceived Competence and Social Acceptance for Young Children. This would provide direct information on self-esteem and social interactions from the child's point of view, thus reducing the reliance upon outside observation and the effects of rater bias.

4. Conduct further research on the development of children's emotional awareness and feeling words vocabulary in play therapy through the creation of an instrument which measures a child's feeling words vocabulary. 
Suggestions for Enhancement of Speech Therapy Services

1. Train all speech therapists in how to make child-centered therapeutic responses.

2. Incorporate a time of non-directive free play into speech therapy programs for children with expressive language delays. Speech therapists should utilize facilitative responses as outlined by Landreth (2002, pp. 207-223) during this time.

3. Consider a multidisciplinary approach to speech therapy, incorporating nondirective, play-based strategies, particularly in the areas of expressive and receptive language delays. 
APPENDIX A

SUMMARY OF RELATED RESEARCH 


\section{SUMMARY OF RELATED RESEARCH}

\begin{tabular}{|c|c|c|c|c|c|}
\hline Author & Year & Field & Type of Study & Format & Results \\
\hline Adams, C. & 1999 & Speech & Research Study & $\begin{array}{l}\text { Semi-structured } \\
\text { play in dyads }\end{array}$ & Increased pro-social behavior in children aged 2-9 \\
\hline $\begin{array}{l}\text { Andronico, M } \\
\text { Blake, I }\end{array}$ & 1971 & Counseling & Case Study & Filial therapy* & Reduction of stuttering \\
\hline $\begin{array}{l}\text { Barlow, K. } \\
\text { Strother, J. } \\
\text { Landreth, G. }\end{array}$ & 1986 & Counseling & Case Study & $\begin{array}{l}\text { Sibling group play } \\
\text { therapy } *\end{array}$ & Increased verbal language from a 5 year-old elective mute \\
\hline Benjamin, B. & 1984 & Speech & Research Study & Role-play & Improvement in phonological deviation of $/ \mathrm{r} /$ \\
\hline Bevins, $\mathrm{S}$. & 1970 & Counseling & Research Study & Group play & Improved social adjustment in $5^{\text {th }}-6^{\text {th }}$ grade students \\
\hline Bouillion, K. & 1973 & Counseling & Research Study & Group play* & Improved articulation in children 3-6 years old \\
\hline $\begin{array}{l}\text { Boulanger, } \mathrm{M} . \\
\text { Langevin, } \mathrm{C} .\end{array}$ & 1992 & Counseling & Research Study & Group play & Improved social skills in 5 year-old boys \\
\hline Boyd, N. & 1944 & Counseling & Case Study & Group play & Increase in self-confidence and social skills \\
\hline $\begin{array}{l}\text { Brooks, A. } \\
\text { Benjamin, B. }\end{array}$ & 1989 & Speech & Research Study & Role-play & Increase in production accuracy of grammatical forms \\
\hline Burlingham, S. & 1938 & Counseling & Case Study & Group play & \\
\hline Bushbacher, P. & 1999 & Speech & Case Study & Group play & Improved social skills in 3 year-old boys \\
\hline Cowden, S. & 1992 & Counseling & Research Study & Group play $^{*}$ & A progression towards higher self-concept \\
\hline Crow, M. & 1971 & Counseling & Research Study & Group play & Gains in self-esteem among $6^{\text {th }}$ graders \\
\hline $\begin{array}{l}\text { DeMaria, M. } \\
\text { Cowden, S. }\end{array}$ & 1992 & Counseling & Case Study & Group play* & $\begin{array}{l}\text { Improved social skills in a } 6 \text { year-old girl } \\
\text { Reduced anxiety in a } 7 \text { year-old girl }\end{array}$ \\
\hline $\begin{array}{l}\text { Donahue, L. } \\
\text { Hartas, D. }\end{array}$ & 1992 & Speech & Research Study & Home play sessions & Increase in intelligible utterances \\
\hline $\begin{array}{l}\text { Dupont. H. } \\
\text { Landsman, T. } \\
\text { Valentine, M. }\end{array}$ & 1953 & Counseling & Case Study & $\begin{array}{l}\text { Individual } \\
\text { play therapy* }\end{array}$ & $\begin{array}{l}\text { Decrease in omission of phonetic sounds in an } 8 \text { year-old } \\
\text { boy }\end{array}$ \\
\hline $\begin{array}{l}\text { Fleming, L. } \\
\text { Snyder, W. }\end{array}$ & 1947 & Counseling & Research Study & Group play* & $\begin{array}{l}\text { Improved sociometric acceptance } \\
\text { Increase in positive feelings towards self }\end{array}$ \\
\hline
\end{tabular}

* denotes child-centered play therapy following the Axline principles 


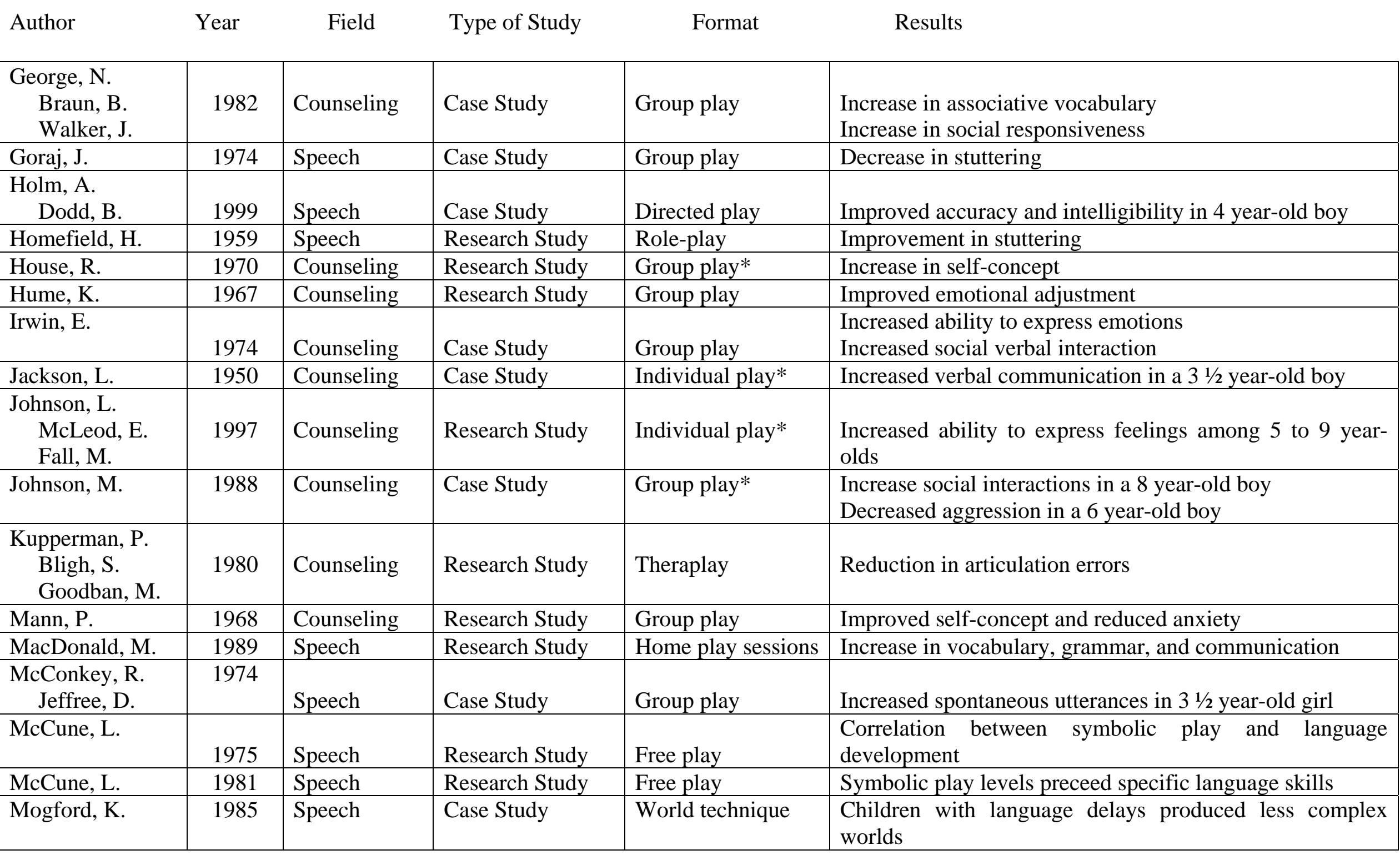

* denotes child-centered play therapy following the Axline principles 

Author
Year
Field Type of Study
Format
Results

\begin{tabular}{|c|c|c|c|c|c|}
\hline Moulin, E. & 1970 & Counseling & Research Study & Group play* & Increased meaningful language use \\
\hline Orphan, D. & 1961 & Counseling & Case Study & $\begin{array}{l}\text { Directed group } \\
\text { play }\end{array}$ & $\begin{array}{l}\text { Improved speech and socialization among physically } \\
\text { handicapped children }\end{array}$ \\
\hline Pelham, L. & 1971 & Counseling & Research Study & Group play* & More developed self-concepts among kindergarteners \\
\hline $\begin{array}{l}\text { Rescorla, L. } \\
\text { Goossens, M. }\end{array}$ & 1992 & Speech & Research Study & Free play & $\begin{array}{l}\text { Less symbolic play among expressive language delayed } \\
\text { three year-olds }\end{array}$ \\
\hline Reymert, M. & 1946 & Counseling & Case Study & $\begin{array}{l}\text { Directed group } \\
\text { play }\end{array}$ & Reduction of stuttering in a 7 year-old boy \\
\hline Rossetti, L. & 1996 & Speech & Case Study & Home play sessions & Increased verbal responsiveness \\
\hline Rustin, L. & 1996 & Speech & Research Study & Free play & Decreased periods of dysfluency \\
\hline $\begin{array}{l}\text { Scherer, N. } \\
\text { D'Antonio, L. }\end{array}$ & 1997 & Speech & Research Study & Free play & $\begin{array}{l}\text { Correlation between vocabulary development and } \\
\text { symbolic play }\end{array}$ \\
\hline Schiffer, A. & 1965 & Counseling & Research Study & Group play* & Stabilized peer relations \\
\hline $\begin{array}{l}\text { Smathers, S. } \\
\text { Tirnauer, L. }\end{array}$ & 1959 & Speech & Case Study & Group play* & $\begin{array}{l}\text { Attainment of age appropriate speech and decreased } \\
\text { aggression }\end{array}$ \\
\hline Sokoloff, M. & 1959 & Counseling & Research Study & Group play* & Improved communication for cerebral palsied children \\
\hline $\begin{array}{l}\text { Terrell, B. } \\
\text { Schwartz, R. } \\
\text { Prelock, P. } \\
\text { Messick, C. }\end{array}$ & 1984 & Speech & Research Study & Free play & $\begin{array}{l}\text { Correlation between vocabulary development and } \\
\text { symbolic play }\end{array}$ \\
\hline $\begin{array}{l}\text { Thombs, M. } \\
\text { Muro, J. }\end{array}$ & 1973 & Counseling & Research Study & Group play & Improved social status among second graders \\
\hline Trostle, $\mathrm{S}$. & 1988 & Counseling & Research Study & Group play* & Increased level of symbolic play \\
\hline $\begin{array}{l}\text { Wade, K. } \\
\text { Haynes, W. }\end{array}$ & 1986 & Speech & Research Study & Child-led play & $\begin{array}{l}\text { No significant difference in spontaneous language } \\
\text { production than in therapist-led interventions }\end{array}$ \\
\hline Wakaba, Y. & 1983 & Speech & Research Study & Group play* & Increased social maturity and decreased stuttering \\
\hline Westby, C. & 1980 & Speech & Research Study & Free play & $\begin{array}{l}\text { No child's meaningful use of language exceeded the } \\
\text { symbolic play level }\end{array}$ \\
\hline
\end{tabular}

* denotes child-centered play therapy following the Axline principles 
APPENDIX B

INFORMED CONSENT FORM 


\section{UNIVERSITY OF NORTH TEXAS \\ COMMITTEE FOR THE PROTECTION OF HUMAN SUBJECTS \\ RESEARCH CONSENT FORM \\ Page 1 of 3}

Subject Name:

Date:

Title of Study: Child-centered Group Play Therapy With Children With Speech

Difficulties

Principle Investigator: $\underline{\text { Suzan }}$

Danger

Co-Investigators:

Before agreeing to participate in this research study, it is important that you read and understand the following explanation of the proposed procedures. It describes the procedures, benefits, risks, and discomforts of the study. It also describes the alternative treatments that are available to you and your right to withdraw from the study at any time. It is important for you to understand that no guarantees or assurances can be made as to the results of the study.

\section{PURPOSE OF THE STUDY AND HOW LONG IT WILL LAST:}

You and your child are invited to participate in a research study to determine if group play therapy is an effective way of helping children who have speech difficulties. The purpose of the study is to find out if group play therapy is helpful in improving speech, improving self-esteem, and improving social skills among children with speech difficulties.

If you agree to allow your child to participate, your child will receive one 30minute group play therapy session every week for approximately 25 weeks during the course of the 2001-2002 school year.

\section{DESCRIPTION OF THE STUDY INCLUDING THE PROCEDURES TO BE} USED:

Group play therapy is a special kind of therapy unlike the regular speech therapy your child receives. If you agree to allow your child to participate in this study, your child, in addition to participating in the regularly scheduled speech therapy sessions provided at Tenderfoot Primary School, will also participate in a 30 minute play session once a week for 25 weeks with another child of approximately the same age (no more than one year older or one year younger than your child) who is also in the speech therapy program. These play sessions are not planned-out activities designed by the researcher. Your child is free to play with a specially selected group 
of toys in the playroom at Tenderfoot Primary School, and the researcher's role is to provide verbal responses to your child, based on their play and language, that communicate acceptance and understanding. The researcher will not ask your child any questions or direct your child's play in any way except to make sure your child does not hurt him/her self, another child, or cause damage to the toys or the room.

There will be two phases for this study. In the first phase, 15 children will be randomly chosen from all of the children whose parents agree to allow them to participate in this study. This selected group will receive 30-minute group play therapy sessions once a week for 25 weeks. In the second phase of the study, after the first group has completed all 25 sessions, those children who were not originally chosen will receive 30-minute group play therapy sessions once a week for the remainder of the school year.

UNIVERSITY OF NORTH TEXAS

COMMITTEE FOR THE PROTECTION OF HUMAN SUBJECTS

RESEARCH CONSENT FORM

Page 2 of 3

Subject Name:

Date:

Title of Study: Child-centered Group Play Therapy With Children With Speech $\underline{\text { Difficulties }}$

Principle Investigator: $\underline{\text { Suzan }}$

Danger

Co-Investigators:

\section{DESCRIPTION OF PROCEDURES/ELEMENTS THAT MAY RESULT IN DISCOMFORT OR INCONVENIENCE:}

There is no personal risk or discomfort directly involved with this study. Your participation and your child's participation are completely voluntary. You may withdraw your child at any time during the course of the study.

At the beginning of the study, regardless of whether your child is randomly chosen to participate in the first phase or the second phase, you will receive a questionnaire, the Burks' Behavior Rating Scale, which is a list of questions concerning the typical behaviors you see in your child on a daily basis. You will be asked to fill out this questionnaire at home, which takes approximately 15-20 minutes to complete, and return it directly to the researcher at Tenderfoot Primary School. You will also be asked to complete the Burks' Behavior Rating Scale at the end of the study, during the second week of April, and return it directly to the researcher at Tenderfoot Primary School. 
DESCRIPTION OF THE PROCEDURES/ELEMENTS THAT ARE ASSOCIATED WITH FORSEEABLE RISKS:

Because this study is designed to test how well group play therapy helps children who have speech difficulties, there is an outside risk that the reverse effects will be achieved, namely, that there will be no improvement of speech difficulty outside the regularly scheduled speech interventions, no improvements in self-esteem, and no improvements in social interaction with other children. If, during the course of the study, the researcher notices any harmful effects, the sessions will be stopped. Researchers who study group play therapy have found no harmful effects of the group play therapy process with children with speech difficulties. In fact, many previous studies indicate that group play therapy improves articulation skills, social skills, and self-esteem (Sokoloff, 1959; Moulin, 1970; Bouillion, 1973; Irwin,m 1974; Wakaba, 1983).

\section{BENEFITS TO THE SUBJECTS OR OTHERS:}

The possible benefits to your child can include: (1) additional improvements in the specific speech difficulty your child is currently experiencing, (2) improvements in overall self-esteem, and (3) improvements in social interactions with other children.

\section{CONFIDENTIALITY OF RESEARCH RECORDS:}

All information will be kept confidential. Names of parents and children will not be disclosed in any publication or discussion of this material. Information obtained from the instruments will be recorded with a code number. Only the investigator will have a list of the paraticipant's names.

UNIVERSITY OF NORTH TEXAS

COMMITTEE FOR THE PROTECTION OF HUMAN SUBJECTS

RESEARCH CONSENT FORM

Page 3 of 3

Subject Name:

Date:

Title of Study: Child-centered Group Play Therapy With Children With Speech $\underline{\text { Difficulties }}$

Principle Investigator: Suzan

Danger

Co-Investigators:

\section{REVIEW FOR PROTECTION OF PARTICIPANTS:}


This research study has been reviewed and approved by the UNT Committee for the Protection of Human Subjects (940) 565-3940.

RESEARCH SUBJECTS' RIGHTS: I have read or have had read to me all of the above.

Suzan Danger has explained the study to me and answered all of my questions. I have been told the risks or discomforts and possible benefits of the study. I have been told of other choices of treatment available to me.

I understand that my child does not have to participate in this study, and my refusal to allow my child to participate will involve no penalty or loss of rights to which my child is entitled. I may withdraw my child at any time without penalty or loss of benefits to which my child is entitled. The study personnel can stop my child's participation at any time if it appears to be harmful to my child, if I or my child fail to follow directions for participation in the study, if it is discovered that my child does not meet the study requirements, or if the study is cancelled.

In case there are problems or questions, I have been told that I can call Suzan Danger at telephone number (940) 458-5681 or Dr. Garry Landreth at telephone number (940) 565-2916). I understand my child's rights as a research subject, and I voluntarily consent to allow my child to participate in this study. I understand what the study is about and how and why it is being done. I will receive a signed copy of this consent form.

\section{For the Investigator or Designee:}

I certify that I have reviewed the contents of this form with the person signing above, who, in my opinion, understood the explanation. I have explained the known benefits and risks of the research. 
APPENDIX C

SUBJECTIVE RATING SCALE 
Session Number

Code Number

Non-Verbally Expressive

Verbally Expressive

\begin{tabular}{|l|l|l|l|l|l|l|l|l|l|}
\hline 1 & 2 & 3 & 4 & 5 & 6 & 7 & 8 & 9 & 10 \\
\hline
\end{tabular}

Isolated

\begin{tabular}{l|l|l|l|l|l|l|l|c|}
\multicolumn{10}{l}{ Connected } \\
\hline 2 & 3 & 4 & 5 & 6 & 7 & 8 & 9 & 10 \\
\hline
\end{tabular}

Session Number

Non-Verbally Expressive

Verbally Expressive

\begin{tabular}{|l|l|l|l|l|l|l|l|l|l|}
\hline 1 & 2 & 3 & 4 & 5 & 6 & 7 & 8 & 9 & 10 \\
\hline
\end{tabular}

Isolated

\begin{tabular}{|l|l|l|l|l|l|l|l|l|l|}
\hline 1 & 2 & 3 & 4 & 5 & 6 & 7 & 8 & 9 & 10 \\
\hline
\end{tabular}

Session Number

Non-Verbally Expressive

Verbally Expressive

\begin{tabular}{|l|l|l|l|l|l|l|l|l|l|}
\hline 1 & 2 & 3 & 4 & 5 & 6 & 7 & 8 & 9 & 10 \\
\hline
\end{tabular}

Isolated

\begin{tabular}{l|l|l|l|l|l|l|l|c|}
\multicolumn{1}{l}{ Connected } \\
\hline 2 & 3 & 4 & 5 & 6 & 7 & 8 & 9 & 10 \\
\hline
\end{tabular}

Session Number

Non-Verbally Expressive

\begin{tabular}{|c|c|c|c|c|c|c|c|c|c|}
\hline 1 & 2 & 3 & 4 & 5 & 6 & 7 & 8 & 9 & 10 \\
\hline
\end{tabular}

Isolated 


\section{REFERENCES}

Adams, C. E. (1999). Older siblings implementing language interventions with younger siblings who have language delays: Effects on sibling interactions during semi-structured play (Doctoral dissertation, University of Kentucky, 1999). Dissertation Abstracts International, 60, DA9948822.

American Psychiatric Association. (1994). Diagnostic and statistical manual of mental disorders $\left(4^{\text {th }}\right.$ ed.). Washington, DC: Author.

Andronico, M. P., \& Blake, I. (1971). The application of filial therapy to young children with stuttering problems. Journal of Speech and Hearing Disorders, 36(6), $377-381$.

Audet, L. R., Burke, G. M., Hummel, L. J., Maher, S. R., \& Theadore, G. (1990). Communication disorders and emotional/behavioral disorders in children and adolescents. Journal of Speech and Hearing Disorders, 55, 179-192.

Axline, V. M. (1947). Play therapy. New York: Ballantine.

Barlow, K., Strather, J., \& Landreth, G. (1986). Sibling group play therapy: an effective alternative with an elective mute child. The School Counselor, 34(1), 44-50.

Benjamin, B. J. (1984). Phonological deviation of $/ r /$ :Remediation utilizing structured role play therapy. Paper presented at the Annual Convention of the Southern Speech Communication Association (Baton Rouge, LA, April 1984).

Bitler, A., DiGaudio, A. B., \& Johnson, C. E. (1976). Communication and play: Observations of play themes in therapy with communication handicapped children. The Publication, 4(4), 74-81.

Bloom, L. \& Lahey, M. (1978). Language development and language disorders. New York: John Wiley \& Sons. 
Bloom, L. (1993). The transition from infancy to language. New York: Cambridge University Press.

Bouillion, K. R. (1973). The comparative efficacy of non-directive group play therapy with preschool, speech, or language delayed children (Doctoral dissertation, Texas Tech University, 1973). Dissertation Abstracts International, $35 \mathrm{O} 1 \mathrm{~B}$.

Boulanger, M. D., \& Langevin, C. L. (1992). Direct observations of play group therapy for social skills deficits. Journal of Child and Adolescent Group Therapy, 2(4), 227-236.

Boyd, N. (1944). Some experiment in group work and play as related to change in social behavior. Welfare Bulletin of the Illinois State Department, 35, 17-19.

Briker, W. A. \& Brickerk, D. D. (1974). An early language training strategy. In R. Scheiflebusch and L. Lloyd (Eds.), Language perspectives. Baltimore: University Park Press.

Broen, P. A., \& Westman, M. J. (1990). Project parent: A preschool speech program implemented through parents. Journal of Speech and Hearing Disorders, 55, 495502.

Brooks, A., \& Benjamin, B. (1989). The use of structured role play therapy in the remediation of grammatical deficits in language delayed children: Three case studies. Journal of Childhood Communication Disorders, 12(2), 171-186.

Burlingham, S. (1938). Therapeutic effects of play group for preschool children. American Journal of Orthopsychiatry, 8, 627-638.

Buschbacher, P. J. (1999). Social linguistic interactions between two young children with disabilities and their play partners (Doctoral dissertation, University of Cincinnati, 1999). Dissertation Abstracts International, 60, DA99375331. 
Cogher, L.. (1999). The use of non-directive play therapy in speech and language therapy. Child Language Teaching and Therapy, 15, 7-15.

Cowden, S. (1992). The effects of child-centered group play therapy on self-concept. Unpublished doctoral dissertation, University of West Florida.

DeMaria, M., \& Cowden, S. (1992). The effects of client-centered group play therapy on self-concept. International Journal of Play Therapy, 1 (1), 53-67.

Donahue, M., \& Hartas, D. (1999). Research on interactions among oral language and emotional behavior disorders. In D. Rogers-Adkinson, \& P. Griffith (Eds.), Communication disorders and children with psychiatric and behavioral disorders (pp. 90-114). San Diego, CA: Singular.

Donahue-Kilburg, G. (1992). Family centered early intervention for communication disorders. Gaithersburg, MD: Aspen.

Dupont, H. J., Landsman, T., \& Valentine, M. (1953). The treatment of delayed speech by client centered therapy. Journal of Consulting Psychology, 17, 122-125.

Ervin-Tripp, S. (1991). Play in language development. In B. Scales, M. Almy, A. Nicolopoulou, \& S. Ervin-Tripp (Eds.), Play and the social context of development in early care and education (pp. 98-117). New York: Columbia University Press.

Fleming, L., \& Snyder, W. (1947). Social and personal changes following nondirective group play therapy. American Journal of Orthopsychiatry, 17, 101-116.

Formaad, W. (1974). Articulation therapy through play: A multi-sensory approach. Glen Ridge, NJ: Exceptional Press. 
Gall, M. D., Borg, W. R., \& Gall, J. P. (1996). Educational Research. White Plains, NY: Longman.

George, N. M., Braun, B. A., \& Walker, J. M. (1982). A prevention and early intervention mental health program for disadvantaged preschool children. The American Journal of Occupational Therapy, 36(2), 99-106.

Goraj, J. (1974). Stuttering therapy as crisis intervention. British Journal of Disorders of Communication, 9(1), 51-57.

Hart, V. (1976). The special child and his play behaviors. The Publication, May 1976, 67-81.

Heppner, P. P., Kivlighan, D.M., \& Wampold, B. (1999). Research design in counseling. Belmont, CA: Wadsworth Publishing

Hoff, E. (2001). Language development. Belmont, CA: Wadsworth Thomson Learning.

Holm, A., \& Dodd, B. (1999). An intervention case study of a bilingual child with phonological disorder. Child Language Teaching and Therapy, 15, 139-158.

House, R. (1970). The effects of non-directive group play therapy upon the sociometric status and self-concept of selected second grade children. Unpublished doctoral dissertation, Oregon State University.

Hubbell, R. D. (1981). Children's language disorders: An integrated approach. Englewood Cliffs, NJ: Prentice-Hall.

Irwin, E. C. (1974). Play therapy for children with cleft palates. Children Today, 3(3), 18-22.

Irwin, R. B. (1974). Language of culturally deprived children. Acta Symbolica, 3(2), 129-132. 
Jackson, L. (1950). Non-speaking children. In G. Landreth, L.E. Homeyer, G.

Glover, \& D. S. Sweeney (Eds.), Play therapy interventions with children's problems (pp. 237-239). Northvale, NJ: Aronson.

James, D. O. (1977). Play therapy: An overview. New York: Dabor Science.

Johnson, L., McCleod, E. H., \& Fall, M. (1997). Play therapy with labeled children in the schools. Professional School Counselor, 1(1), 31-34.

Johnson, M. (1988). Use of play group therapy in promoting social skills. Issues in Mental Health Nursing, 9(1), 105-112.

Klein, H. B., \& Moses, N. (1999). Intervention planning for children with communication disorders: A guide for clinical practicum and professional practice. Needham Heights, MA: Allyn \& Bacon.

Kovarsky, D. (1990). Discourse markers in adult-controlled therapy: Implications for child-centered interventions. Journal of Childhood Communication Disorders, 13(1), $29-43$

Kraus, L. E., Stoddard, S., \& Gilmartin, D, (1996). Chartbook on Disabilities in the United States. United States Department of Education.

Kupperman, P., Bligh, S., \& Goodban, M. (1980). Activating articulation skills through theraplay. Journal of Speech and Hearing Disorders, 45(4), 540-548.

Landreth, G., Jacquot, W. S., \& Allen, L. (1969). A team approach to learning disabilities. Journal of Learning Disabilities, 2, 24-29.

Landreth, G. (1991). Play therapy: The art of the relationship. Bristol, PA: Accelerated Development.

Landreth, G. (2002). Play therapy: The art of the relationship ( $2^{\text {nd }}$ ed.). New York: Brunner-Routledge. 
Landreth, G., \& Sweeney, D. S. (1999). The freedom to be: Child-centered group play therapy. In D. Sweeney \& L. Homeyer (Eds.), The handbook of group play therapy. San Francisco, CA: Jossey-Bass.

Leland, H. (1982). Play therapy with the non-verbal. Paper presented at the Annual Meeting of the American Psychological Association (Washington, DC, August, 1982).

Levenstien, P. (1985). Mother's interactive behavior in play sessions and children's educational achievement. In C. C. Brown \& A. W. Gottfried (Eds.), Play interactions: The role of toys and parental involvement in children's development (pp. 160-167). Skillman, NJ: Johnson \& Johnson.

MacDonald, J. D. (1989). Becoming partners with children: From play to conversation. Chicago, IL: Riverside.

Martin, J. A. (1981). Voice, speech, and language in the child: Development and disorder. New York: Springer-Verlag.

McAndrew, E. (1999). The relationship between self-esteem and language disorders. Child Language Teaching and Therapy, 15, 219-232.

McConkey, R. (1976). Extending language through play. Journal of Child Psychology and Psychiatry, 17, 189-197.

McCormick, L., \& Scheiflebusch, R. L. (1984). Early language intervention. Colombus, OH: Charles E. Merrill.

McCune-Nicolich, L. (1975). A longitudinal study of representational play in relation to spontaneous imitation and development of multi-word utterances. Paper presented to the National Institute of Education Project. 
McCune-Nicolich, L. (1981). Toward symbolic functioning: Structure of early pretend games and potential parallels with language. Child Development, 52, 785797.

McGregor, D. (1993). Self-building: Enhancing self-esteem through group play therapy. Association for Play Therapy Newsletter, 3(3), 2-4.

Mogford-Bevin, K. P. (1994). Play assessment for play-based interventions: A first step with young children with communication difficulties. In Hellendoorn, R. van der Kooij, \& B. Sutton-Smith (Eds.), Play and intervention (pp. 157-173). Albany, NY: State University of New York.

Moulin, E. K. (1970). The effects of client-centered group counseling using play media on the intelligence, achievement, and psycholinguistic abilities of underachieving primary school children. Elementary School Guidance and Counseling, 5(8), 81-95.

National Center of Health Statistics (1999). America's Children. Retrieved 2001 from http:// www.childstats.gov.

Norusis, M. (1995). SPSS 6.1: Guide to data analysis. Englewood Cliffs, NJ: Prentice-Hall.

O’Connor, K. J. (1991). The play therapy primer. New York: John Wiley \& Sons. Office of Educational Research and Improvement (1990). Children with communication disorders. Washington, DC, 1990.

Orphan, D. (1961). Play therapy helps handicapped kids. Today's Health, 39, 54-57.

Pelham, L. (1971). Self-directed play therapy with socially immature kindergarten students. Unpublished doctoral dissertation, University of Northern Colorado. Piaget, J. (1959). The language and thought of the child. New York: Humanities. 
Piaget, J. (1962). Play dreams, and imitiation in childhood. New York: W. W.

Norton.

Ray, D., Bratton, S., Rhine, T., \& Jones, L. (2001). The effectiveness of play therapy: Responding to the critics. International Journal of Play Therapy, 10(1), 85108.

Rescorla, L. \& Goossens, M. (1992). Symbolic play development in toddlers with expressive specific language impairment. Journal of Speech and Hearing Research, $35,1290-1302$.

Reymert, M. (1946). Play therapy at Mooseheart. Journal of Exceptional Children, $13,2-9$.

Ritter, P. S. \& Fokes, J. (1985). Applying play to therapy. Paper presented at the Annual Convention of the American Speech-Language-Hearing Association (Washington DC, November, 1985).

Rossetti, L. M. (1996). Communication intervention. San Diego, CA: Singular.

Rustin, L., Botterill, W., \& Kelman, E. (1996). Assessment and therapy for young dysfluent children. London: Whurr.

Scherer, N. J. \& D'Antonio, L. (1997). Language and play development in toddlers with cleft lip and/or palate. American Journal of Speech-Language Pathology, 6(4), $48-54$

Schiffer, A. (1965). The effectiveness of group play therapy as assessed by specific changes in a child's peer relations. Unpublished doctoral dissertation, Michigan State University.

Seitz, S. \& Riedell, G. (1974). Parent-child interactions as the therapy target. Journal of Communication Disorders, 7, 295-304. 
Smathers, S. \& Tirnauer, L. (1959). Speech play therapy. Journal of Speech and Hearing Disorders, 24, 59-61.

Smith, D. M. \& Smith, N. R. (1999). Relational activity play therapy group: A stopping off place for children on their journey to maturity. In D. Sweeney \& L. Homeyer (Eds.), The handbook of group play therapy. San Francisco, CA: JosseyBass.

Smith, D. M. (2002). Filial therapy with teachers of deaf and hard of hearing preschool children. Unpublished doctoral dissertation, University of North Texas.

Sokoloff, M. A. (1959). A comparison of gains in communicative skills, resulting from group play therapy, among a group of non-severely dysthartic, speech handicapped cerebral palsied children. In G. Landreth, L. Homeyer, G. Glover, \& D. Sweeney (Eds.), Play therapy interventions with children's problems (pp. 237-239). Northvale, NJ: Aronoson.

Sweeney, D. \& Homeyer, L. (1999). The handbook of group play therapy. San Francisco, CA: Jossey-Bass.

Trostle, S. L. (1988). The effects of child-centered group play therapy sessions on the social and emotional growth of three to six year old bilingual puerto rican children. Journal of Research in Childhood Education, 3(2), 93-106.

Ungerer, J. \& Sigman, M. (1984). Cognitive and language skills in autistic, mentally retarded and normal children. Developmental Psychology, 20, 293-302.

Vygotsky, L. S. (1933). Play and its role in the mental development of the child. In J. S. Bruner, A. Jolly, \& K. Sylva (Eds.), Play (pp. 537-555). New York: Basic Books. 
Wade, K. M. \& Haynes, W. O. (1986). Dynamic assessement of spontaneous language and cue responses in adult-directed and child-directed play: A statistical and descriptive analysis. Child Language Teaching and Therapy, 12, 157-173.

Wakaba, Y. Y. (1983). Group play therapy for japanese children who stutter. Journal of Fluency Disorders, 8, 93-118.

Werner, H. \& Kaplan, B. (1963). Symbol formation. New York: John Wiley \& Sons.

Westby, C. (1980). Assessment of cognitive and language abilities through play. Language, Speech, and Hearing Services in Schools, 11, 154-168.

Wing, L., Gould, J., Yeats, S. R. \& Brierley, L. M. (1977). Symbolic play in severely mentally retarded and in autistic children. Journal of Child Psychology and Psychiatry, 18, 167-178. 